\title{
DANIELLA MORAES ANTUNES
}

Efeito dos tratamentos com ácido acetilsalicílico e celecoxibe na expressão de citocinas e no comportamento de linhagens celulares de carcinoma epidermoide de boca

São Paulo 


\section{DANIELLA MORAES ANTUNES}

Efeito dos tratamentos com ácido acetilsalicílico e celecoxibe na expressão de citocinas e no comportamento de linhagens celulares de carcinoma epidermoide de boca

\section{Versão Corrigida}

Tese apresentada à Faculdade de Odontologia da Universidade de São Paulo, para obter o título de Doutor, pelo Programa de Pós-Graduação em Odontologia.

Área de Concentração: Patologia e Estomatologia Básica e Aplicada.

Orientador: Prof. Dr. Fabio Daumas Nunes

São Paulo 
Autorizo a reprodução e divulgação total ou parcial deste trabalho, por qualquer meio convencional ou eletrônico, para fins de estudo e pesquisa, desde que citada a fonte.

Catalogação da Publicação

Serviço de Documentação Odontológica

Faculdade de Odontologia da Universidade de São Paulo

Antunes, Daniella Moraes.

Efeito dos tratamentos com ácido acetilsalicílico e celecoxibe na expressão de citocinas e no comportamento de linhagens celulares de carcinoma epidermoide de boca / Daniella Moraes Antunes ; orientador Fábio Daumas Nunes. -- São Paulo, 2015.

61 p. : fig., tab. ; $30 \mathrm{~cm}$.

Tese (Doutorado) -- Programa de Pós-Graduação em Odontologia. Área de Concentração: Patologia e Estomatologia Básica e Aplicada. -- Faculdade de Odontologia da Universidade de São Paulo.

Versão corrigida.

1. Aspirina. 2. Neoplasias bucais. 3. Carcinoma de células escamosas. 4. Citocinas. I. Nunes, Fábio Daumas. II. Título. 
Antunes DM. Expressão gênica de citocinas em linhagens de carcinoma epidermoide de cavidade oral após tratamento com ácido acetilsalicílico e celecoxibe. Tese apresentada à Faculdade de Odontologia da Universidade de São Paulo para obtenção do título de Doutor em Ciências.

Aprovado em: / /2015

\section{Banca Examinadora}

$\operatorname{Prof}(\mathrm{a}) . \operatorname{Dr}(\mathrm{a})$.

Instituição: Julgamento:

$\operatorname{Prof}(\mathrm{a}) . \operatorname{Dr}(\mathrm{a})$.

Instituição: Julgamento:

Prof(a). Dr(a).

Instituição: Julgamento:

Prof(a). $\operatorname{Dr}(\mathrm{a})$.

Instituição: Julgamento:

Prof(a). Dr(a).

Instituição: Julgamento: 
$\mathcal{A}$ Deus, por me orientar, sustentar, por me dar perfeita saúde física e mental. Por encher minha vida de amor e colocar ao meu lado pessoas tão incríveis. Por tornar minha jornada tão incrivel.

À minha amada avó, Línda, por todo o amor que tem por mim e que me ensinou a ter. Por me abençoar e cuidar o tempo todo. Amo você para sempre!

Aos meus amados pais, Ana e Betto, pelo insubstituivel amor. Por serem meus maíres exemplos de gentíleza, bondade, honestidade, força e coragem. Sou muito grata por tudo que sempre fizeram e fazem por mim. Por fazerem de nossa familia um berço de amor $e$ serenidade.

Ao meu amado noivo, Gíuliano, por todo o apoío, companheirísmo, atenção, carínho e mimo. Por ser tão especial. Por trazer tanto amor, paz e alegría à minha vida. Amo você demais!

Aos meus irmãos Díogo e Sarina, à minha cunhada Kelen e ao meu lindo sobrinho Murílo, por todas as palavras e gestos de carinho e apoío. 
Agradeço ao meu orientador, Prof. Fabio Daumas Nunes, pela excelente oportunidade de crescimento pessoal e profissional. Por confiar na minha capacidade e no meu trabalho. Por estar sempre à disposição para ensinar com paciência e entusiasmo.

Agradeço aos professores da disciplina de Patologia Bucal, Décio, Suzana, Marina e Andrea pelos constantes ensinamentos durante as aulas e por compartilharem seus conhecimentos durante as discussões de casos clínicos.

Do fundo do coração agradeço aos verdadeiros amigos Ana Maria, Douglas, Tathy, Carina, Maria Fernanda e Marina, pela sincera amizade, pelo convívio alegre e harmonioso. Por tornarem muito mais agradável essa experiência na pósgraduação. Vocês são amigos que vou levar para a vida toda. Quero agradecer demais à Carina, ao Douglas e a Maria Fernanda por terem me ajudado, com tanta boa vontade e gentileza, nos meus experimentos. Sem essa ajuda a realização deste trabalho não teria sido possível.

Obrigada a todos os colegas da pós-graduação por compartilharem seus conhecimentos e pelo convívio agradável.

Obrigada Adriana, Edna, Elisa, Fátima, Juvani, Néia, Vinicius e Zilda por toda a ajuda, apoio e gentileza durante todas as fases de curso.

Ao Conselho Nacional de Desenvolvimento Científico e Tecnológico (CNPq) pela concessão da bolsa de doutorado, o que tornou possível a realização deste trabalho.

À Faculdade de Odontologia de São Paulo (FOUSP) pelo acolhimento e por permitir acesso e utilização de suas instalações e laboratórios.

À Universidade Federal de Mato Grosso do Sul (UFMS) por permitir que me afastasse de minhas atividades de docência para realização do doutorado. 


\section{RESUMO}

Antunes DM. . Efeito dos tratamentos com ácido acetilsalicílico e celecoxibe na expressão de citocinas e no comportamento de linhagens celulares de carcinoma epidermoide de boca [tese]. São Paulo: Universidade de São Paulo, Faculdade de Odontologia; 2015. Versão Corrigida.

Quatro décadas de pesquisas mostraram que muitos mecanismos inflamatórios estão intrinsecamente ligados ao desenvolvimento e manutenção do câncer, e ainda, que as citocinas inflamatórias exercem papel primordial nessa relação. Os anti-inflamatórios não esteroides (AINEs) podem reduzir o desenvolvimento neoplásico por afetar a produção de citocinas inflamatórias pelas células neoplásicas. No entanto, até o momento não foi bem definido se o tratamento com AINEs é capaz de modular a expressão de citocinas inflamatórias por células do carcinoma epidermoide oral (CEO). O objetivo deste trabalho foi avaliar a expressão de citocinas inflamatórias em linhagens celulares de CEO após tratamento com ácido acetilsalicílico (AAS) e celecoxibe (CLX). Foi realizado screening da expressão de 84 citocinas e quimiocinas, através de PCR array, das linhagens SCC4, 9 e 25 tratadas com doses de AAS e CLX próximas às concentrações plasmáticas dos fármacos em humanos. Os resultados mostraram que AAS e CLX modularam a expressão de citocinas e que as linhagens responderam de maneira diferente aos tratamentos. Observou-se aumento de expressão de citocinas pró-inflamatórias como a IL-1 $\beta$, IL-8 e TNF na SCC9 e 25, assim como diminuição de expressão de ACKR4 e CXCL10 na SCC4 e 9.

Palavras-chave: AAS. Ácido acetilsalicílico. Câncer de boca. Carcinoma epidermoide oral. Celecoxibe. Citocinas. Inflamação. Quimiocinas. 


\begin{abstract}
Antunes DM. Effect of treatment with aspirin and celecoxib on the expression of cytokines and behavior of cell lines of squamous cell carcinoma [thesis]. São Paulo: Universidade de São Paulo, Faculdade de Odontologia; 2015. Versão Corrigida.
\end{abstract}

Four decades of research have shown that many inflammatory mechanisms are intrinsically linked to the development and maintenance of cancer and that inflammatory cytokines play pivotal role in this association. Non-steroidal antiinflammatory drugs (NSAIDs) can reduce neoplastic growth on affecting the production of inflammatory cytokines by the neoplastic cells. So far, it is not well established if the treatment with NSAIDs can modulate the expression of inflammatory cytokines by OSCC cells. The objective of this study was to evaluate the expression of inflammatory cytokines by OSCC cell lines after treatment with acetylsalicylic acid (ASA) and celecoxib (CLX). Eighty-four cytokines and chemokines mRNA expression were screened by PCR array on SCC4, 9 and 25 cell lines treated with ASA and CLX at plasma concentrations in humans. The results showed that ASA and CLX modulate the expression of cytokines with all cell lines responding differently to the treatments. Increased expression of proinflammatory cytokines such as IL-1 $1 \beta$, IL-8 and TNF in SCC9 and 25, and reduced expression of ACKR4 and CXCL10 in SCC4 and 9, was observed. Thus it follows that the treatments of lines SCC4, SCC9 and SCC25 with ASA and CLX at the next plasma concentrations in humans are able to modulate the gene expression of inflammatory cytokines.

Keywords: Aspirin. Acetylsalicylic acid. Celecoxib. Chemokines. Cytokines. Inflammation. Oral Cancer. Oral squamous cell carcinoma. 


\section{LISTA DE FIGURAS}

Figura 5.1 - Representação gráfica da concentração de IL-6, na linhagem SCC9, após tratamento com etanol ou AAS. Os asteriscos representam as diferenças estatísticas entre o grupo marcado e o grupo sem tratamento. ${ }^{*} \mathrm{p}=0,0234 ;{ }^{* *} \mathrm{p}=0,0030,{ }^{* * *} \mathrm{p}<0,0002,{ }^{* \star *} \mathrm{p}<0,0001$

Figura 5.2 - Representação gráfica da concentração de IL-6, na linhagem SCC9, após tratamento com DMSO ou CLX. Os asteriscos representam as diferenças estatísticas entre o grupo marcado e o grupo sem tratamento. ${ }^{*} \mathrm{p}=0,0234 ;{ }^{* *} \mathrm{p}=0,0030$

Figura 5.3 - Representação gráfica da porcentagem de células viáveis, após tratamento com etanol ou AAS. As barras em preto representam as amostras que não receberam nenhum tratamento. Esse grupo foi considerado como tendo $100 \%$ de células viáveis. Os asteriscos representam as diferenças estatísticas entre o grupo marcado e o grupo sem tratamento para cada tempo. ${ }^{* * *} \mathrm{p}<0,001$

Figura 5.4 - Representação gráfica da porcentagem de células viáveis, após tratamento com DMSO ou CLX. As barras em preto representam as amostras que não receberam nenhum tratamento. Esse grupo foi considerado como tendo $100 \%$ de células viáveis. Os asteriscos representam as diferenças estatísticas entre o grupo marcado e o grupo sem tratamento para cada tempo. ${ }^{*} p<0,05$

Figura 5.5 - Genes diferencialmente expressos por qPCR nas linhagens tratadas com AAS em relação ao controle (Etanol)

Figura 5.6 - Genes diferencialmente expressos por qPCR nas linhagens tratadas com CLX em relação ao controle (DMSO) 


\section{LISTA DE ABREVIATURAS E SIGLAS}
AAS Ácido acetilsalicílico
AINE Anti-inflamatório não esteroide
Apc Adenomatous polyposis coli
$\mathrm{Bcl} \quad B$-cell leukemia/lymphoma
$\mathrm{CCL} \quad \mathrm{CC}$ chemokine ligands
CCR CC chemokine receptor
CEO Carcinoma epidermoide oral
CLX Celecoxibe
COX Ciclooxigenase
$\mathrm{CX}_{3} \mathrm{C} \quad \mathrm{CX}_{3} \mathrm{C}$ chemokine ligands
$\mathrm{CXCL} \quad \mathrm{CXC}$ chemokine ligands
CXCR CXC chemokine receptor
DMSO Dimethyl sulfoxide
HIF1 Hypoxia-inducible factor 1
INCA Instituto Nacional de Câncer
INF- $Y \quad$ Interferon $Y$
JAK Janus quinase
MMP Metaloproteinase
MTT (brometo de 3-[4,5-dimetil-tiazol-2-il]-2,5-difeniltetrazólio)
NF-KB Factor nuclear kappa $B$
PAF Polipose adenomatosa familiar
PG Prostaglandinas
SCC Squamous cell carcinoma
STAT Signal transduction and transcription
VEGF Vascular endothelial growth factor
TGF Transforming growth factor
TNF Tumor necrosis factor 
1 INTRODUÇÃO

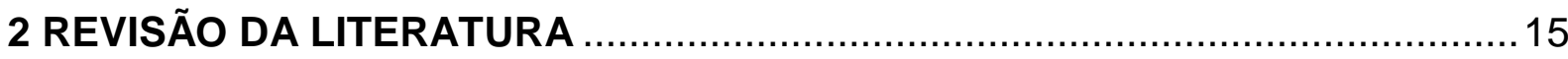

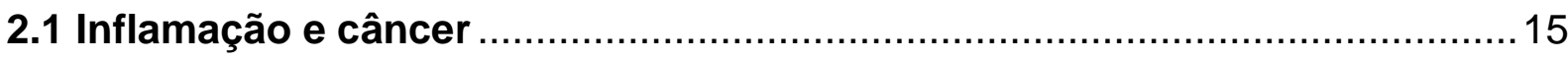

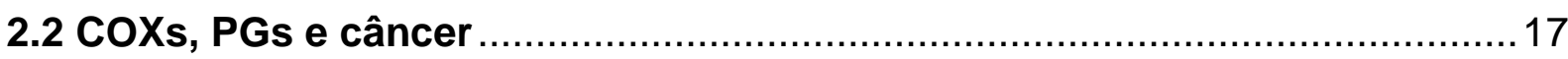

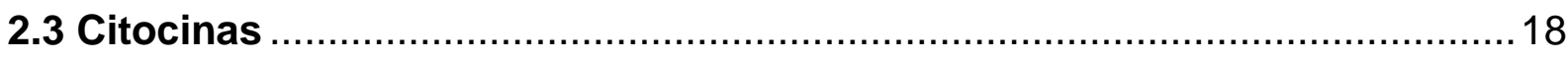

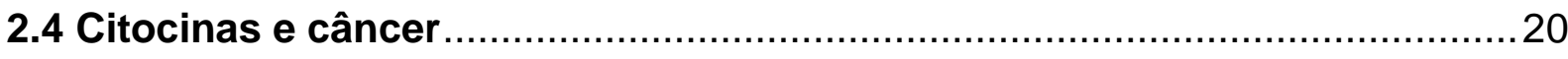

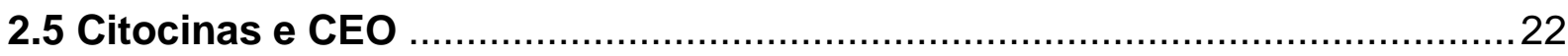

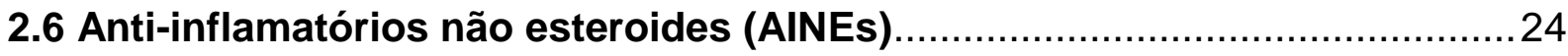

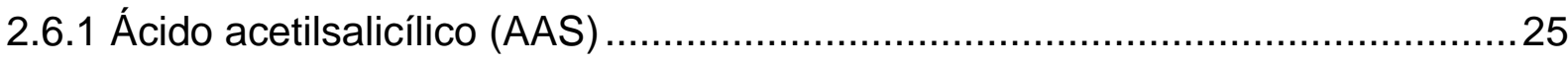

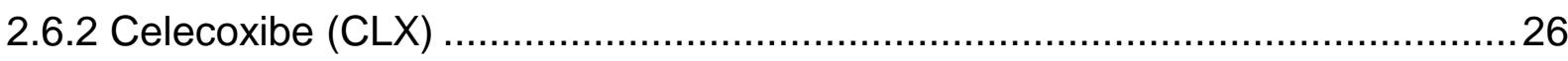

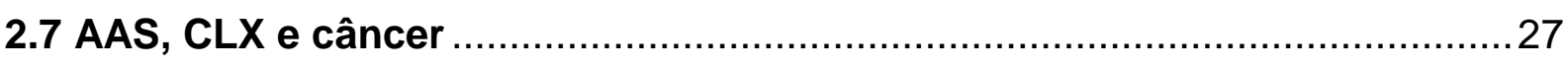

3 PROPOSIÇÃO

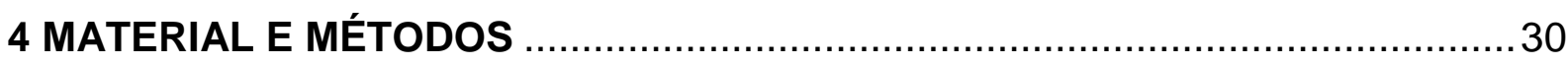

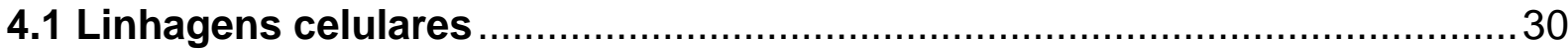

4.2 Tratamento das linhagens com anti-inflamatórios..................................... 30

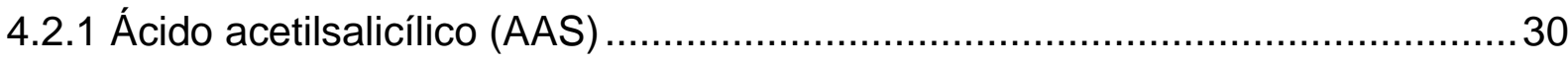

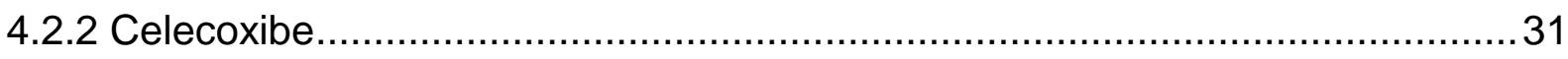

4.3 Ensaio imunoenzimático para IL-6 (ELISA) …........................................... 31

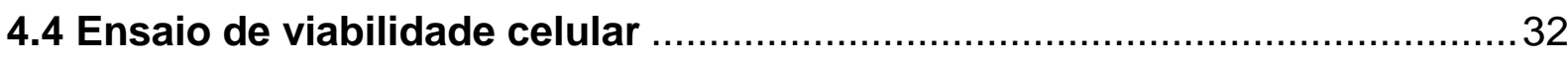

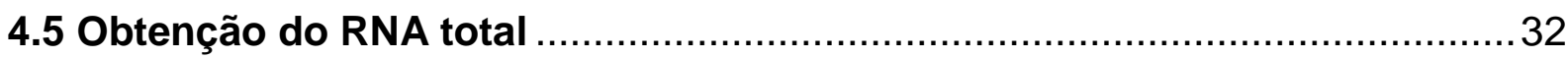



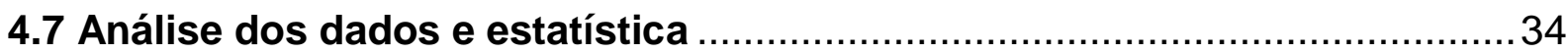




6 DISCUSSÃO 41

7 CONCLUSÃO 46

REFERÊNCIAS .47

ANEXOS .55 


\section{INTRODUÇÃO}

Quatro décadas de pesquisas mostraram que vários mecanismos inflamatórios estão intrinsecamente ligados ao desenvolvimento e manutenção de todas as hallmarks do câncer. Estudos in vitro, in vivo e clínicos mostraram que as citocinas inflamatórias e fatores de crescimento exercem papel primordial nessa relação entre inflamação e câncer. Essas moléculas podem levar a alterações em genes relacionados ao câncer, assim como a modificações em proteínas importantes para controle do ciclo celular, reparo do DNA, apoptose, angiogênese, evasão da imunidade e metástase. Acreditava-se que as citocinas inflamatórias presentes no microambiente neoplásico fossem produzidas somente pelas células inflamatórias, porém hoje sabe-se que as células neoplásicas também produzem e liberam essas moléculas (1-3).

O carcinoma epidermoide oral (CEO), dada sua alta frequência, é considerado sinônimo de câncer de boca. O diagnóstico tardio e a falta de terapias eficientes são as duas principais causas da grande morbidade relacionada a essa neoplasia. Há várias décadas o CEO tem representado grande desafio da saúde pública em muitos países em desenvolvimento, inclusive no Brasil. De acordo com o Instituto Nacional de Câncer foram estimados, para 2014, cerca de 11.280 novos casos de câncer da cavidade oral em homens e 4.010 em mulheres (4).

Assim como em outros tipos de neoplasia, as citocinas e fatores de transcrição têm mostrado grande relevância na relação entre inflamação e câncer de boca. As citocinas pró-inflamatórias IL-1 $\beta$, IL-6 e TNF estão entre as envolvidas nos processos de proliferação celular, apoptose e angiogênese. Várias quimiocinas das famílias CCL e CXCL, juntamente com seus receptores, já foram relacionadas com angiogênese, invasão e metástase do CEO (5-7).

Existe grande complexidade e redundância nas vias de sinalização que coordenam as capacidades desenvolvidas pelas células neoplásicas. Em função disso, terapias que tem como alvo vias específicas estão resultando em resistência tumoral. De fato, as evidências científicas indicam que o sucesso de novos protocolos terapêuticos estão na dependência do desenvolvimento de terapias que incidam sobre a doença em mais de uma de suas características essenciais, e que 
levem em consideração as múltiplas vias de sinalização que suportam cada uma delas $(3,8,9)$. O processo inflamatório associado ao tumor parece ser um excelente candidato a alvo terapêutico, uma vez que está envolvido com o desenvolvimento e/ou manutenção de várias das características essenciais das células neoplásicas.

Os anti-inflamatórios não esteroides (AINEs) são um grupo de fármacos de estrutura química variada que têm como atividades a modulação da inflamação, a analgesia e o controle da hipertermia. Essas substâncias atuam na inibição de enzimas do grupo das ciclooxigenases (COXs), impedindo assim a síntese de eicosanoides $(10,11)$. Os primeiros trabalhos sobre a utilização de AINEs na prevenção e tratamento do câncer surgiram nas décadas de 70 e 80 (12, 13), justamente quando os estudos mostravam aumento da expressão de COXs em condições pré-malignas e tecidos que sofreram transformação maligna $(14,15)$. São muitos os efeitos antineoplásicos dos AINEs, dentre eles está a capacidade de reduzir o desenvolvimento neoplásico por afetar a produção de citocinas inflamatórias e fatores de transcrição relacionados à inflamação.

O uso de AINEs no tratamento do câncer de boca também tem sido estudado, inclusive trabalhos clínicos importantes foram publicados na última década $(6,8,9)$. No entanto, até o momento não foi bem definido se os tratamento com AINEs modulam a expressão de citocinas inflamatórias por células de CEO. Além disso, não foi suficientemente verificado como se dá a expressão dessas moléculas em várias linhagens de CEO, bem como se a modulação dessa expressão, por drogas anti-inflamatórias, afeta o comportamento da célula tumoral. Dessa maneira, o presente estudo teve como objetivo realizar um screening, através da técnica de PCR array, da expressão de 84 citocinas inflamatórias em três linhagens de CEO após tratamento com AAS e CLX usados em concentrações próximas às plasmáicas em humanos. 


\section{REVISÃO DA LITERATURA}

\subsection{Inflamação e câncer}

Estudos relativamente recentes contribuíram para a construção de uma maneira mais lógica de entender o desenvolvimento do câncer. A transformação de um fenótipo normal em maligno envolve a aquisição de características que conferem vantagens ao crescimento celular, são as chamadas hallmarks do câncer (3). Segundo os autores, possibilitando e sustentando essas características estão as mutações e a instabilidade genômica e a inflamação. E realmente, através de experimentos in vitro, trabalhos em animais, estudos epidemiológicos e clínicos, foi possível confirmar uma hipótese elaborada por Virchow em 1863 (1), de que a inflamação estaria relacionada à progressão das neoplasias. Estima-se atualmente que o processo inflamatório crônico seja responsável por um em cada quatro casos de todos os tipos de câncer (16).

O processo inflamatório pode estar presente antes da transformação maligna ocorrer, com é o caso da doença de Crohn e da colite ulcerativa com relação ao carcinoma de cólon; da infecção pelo vírus da hepatite B ou C ou da cirrose alcoólica com o hepatocarcinoma ou dos quadros de prostatite e pancreatite com os carcinomas prostático e pancreático, respectivamente. No entanto, mesmo em neoplasias que a princípio não tem uma base inflamatória, como a de mama ou a de ovário, já tiveram sua evolução relacionada a mecanismos inflamatórios $(17,18)$. Aliás, quando o assunto é neoplasia, os mecanismos inflamatórios parecem estar muito mais relacionados com o desenvolvimento, crescimento e invasão tumoral do que com a eliminação de um agente agressor, reparo tecidual e restabelecimento da homeostase. Em uma revisão clássica, Balkwill e Mantovani (2001) (1), explicam o que se acredita ser a chave da relação inflamação e câncer: a produção e liberação de citocinas e fatores de crescimento no microambiente tumoral. Esses mediadores químicos podem ser produzidos tanto pelas células do estroma tumoral, células 
inflamatórias e fibroblastos, quanto pelas próprias células neoplásicas. Mantovani et al. (2008) (19) relataram que câncer e inflamação podem estar conectados através de duas vias, uma intrínseca e outra extrínseca, e que essas vias têm um ponto de convergência: a produção de fatores de transcrição, principalmente NF-KB, STAT e HIF1 e que esses fatores coordenam a produção de mediadores inflamatórios. Uma vez liberados no microambiente tumoral, citocinas, fatores de crescimento, radicais livres e enzimas como as ciclooxigenases podem levar a alterações em genes relacionados ao câncer, assim como a modificações em proteínas importantes para controle do ciclo celular, reparo do DNA, apoptose, angiogênese, evasão da imunidade e metástase. Mais recentemente a literatura tem mostrado que a liberação de citocinas inflamatórias no microambiente tumoral interfere no equilíbrio entre a população de células tronco e células não tronco de um tumor. Aumentando a população de células tronco, aumenta-se também o risco de metástase e de resistência à quimioterapia $(20,21)$. Citocinas inflamatórias também podem ativar mecanismos de desenvolvimento como os que ocorrem durante a embriogênese ou durante o reparo tecidual, esses mecanismos também são importantes para proliferação e sobrevivência das células tronco, tanto normais quanto tumorais (22). Esse efeito da inflamação sobre as células tronco tumorais foi também abordado em trabalho publicado este ano, segundo o qual o anti-inflamatório celecoxibe foi capaz de diminuir a quimioresistência de células de câncer de bexiga. Segundo os autores esse efeito se deve a inibição de prostaglandinas que podem induzir a repopulação de células tronco tumorais em sítios previamente tratados com quimioterapia (23). 


\subsection{Ciclooxigenases, Prostaglandinas e câncer}

Desde a década de 70 o aumento de expressão de COX em condições prémalignas e tecidos que sofreram transformação maligna vem sendo estudado. Através do uso de inibidores do COXs, células e animais modificados geneticamente, vem sendo possível confirmar o envolvimento dessas enzimas e seus subprodutos durante as várias fases da carcinogênese $(14,15)$.

Embora o aumento da expressão de COX e seus metabólitos, por si só, não seja suficiente para iniciar o tumor, alguns trabalhos mostraram que essas substâncias podem sim desempenhar alguma função na iniciação do câncer. As prostaglandinas podem interferir com a imunidade antitumoral inibindo a produção de citocinas e a função das células NK e macrófagos (15, 24). Estudos in vivo mostraram diminuição significativa no risco de desenvolvimento de neoplasia intestinal e de pele quando havia baixa expressão de COX ou quando esta era inibida (25-27).

Após a iniciação tumoral, alguns mecanismos são essenciais para que 0 tumor continue crescendo. Esses mecanismos estão entre as chamadas hallmarks do câncer. A proliferação celular continuada e sustentada por sinais das próprias células tumorais é apenas um desses mecanismos. Envolvidos na progressão tumoral também estão a capacidade de resistir à apoptose, de induzir a formação de uma rede vascular que continue alimentando o tumor e a capacidade de escapar dos mecanismos de defesa antitumoral do hospedeiro.

Com relação à proliferação celular continuada, estudos revelaram a diminuição significativa de marcadores de proliferação como o Ki-67 em células de carcinoma tratadas com inibidores de COXs (28). A superexpressão dessas enzimas foi notada em tecidos de câncer de próstata que também apresentaram marcado aumento no gene supressor de apoptose Bcl-2 e no fator de crescimento vascular VEGF (29). Fármacos inibidores de COXs, especialmente de COX-2, mostraram-se eficientes também em diminuir a capacidade das células tumorais induzirem a migração de células endoteliais para formação de novos vasos sanguíneos (30).

O aumento da expressão de COX-2 conferiu um fenótipo invasivo em células de câncer de pulmão e cólon. Tal fenótipo mostrou relação com a degradação de elementos da matriz extracelular através do aumento na expressão de 
metaloproteinases (MMPs) 1 e 2, diminuição da adesão célula-célula e dos receptores CD44 $(24,31)$. Foi observada também a relação de alta expressão de COX-2 e VEGF em linfonodos metastáticos de câncer cervical e pulmonar (32). O uso de drogas inibidoras de COX-2 diminuiu os níveis de VEGF no plasma de pacientes com câncer de cabeça e pescoço (33). Essas drogas também foram capazes de reduzir a incidência de metástases em animais com câncer de cólon (34). Elevadas concentrações de COXs e prostaglandinas (PGs), em tumores de mama, já foram relacionadas com desenvolvimento de metástases à distância e pobre prognóstico (35).

Um estudo in vitro e in vivo com células de câncer pulmonar, mostrou que a alta expressão de COX-2, pelas células tumorais, levou ao aumento de expressão das quimiocinas angiogênicas CXCL5 e CXCL8, que por sua vez foi importante para o crescimento tumoral. Segundo os autores, o aumento dessas citocinas parece estar relacionado com a translocação nuclear de NF-KB induzida pela superexpressão tumoral de COX-2 (14).

A alta expressão de COXs e $\mathrm{PGE}_{2}$ mostrou inibir a liberação de quimiocinas CXCL9 e CXCL10 por células de câncer de mama. Como essas quimiocinas estão relacionadas com uma respostas antitumoral realizada por linfócitos T e células NK, os autores concluíram que o uso de drogas que sejam inibidoras de COXs seria uma importante estratégia para aumentar a imunidade contra a neoplasia (15).

\subsection{Citocinas}

Citocinas são moléculas proteicas, geralmente de meia vida curta, que induzem e regulam um grande número de respostas celulares, tanto em condições fisiológicas quanto patológicas. A maioria dessas moléculas está relacionada com o desenvolvimento, maturação e homeostase do sistema imunológico e com as respostas inflamatórias e reparo tecidual. Dentre os tipos celulares que produzem e secretam essas moléculas estão os leucócitos, células endoteliais, células do tecido conjuntivo como macrófagos, plasmócitos e fibroblastos e ainda, alguns tipos de células epiteliais. Uma determinada citocina pode atuar sobre vários tipos celulares, suscitando efeitos diferentes em cada um deles. Para exercerem seus efeitos as 
citocinas precisam ligar-se a receptores localizados na superfície celular ou em elementos da matriz extracelular. O modo de atuação pode ser autócrino, parácrino ou sistêmico. Embora uma mesma molécula possa ter efeitos distintos, as citocinas podem ser classificadas de acordo com suas atividades funcionais, por exemplo: as interleucinas (ILs) 1 e 6 (IL-1 e IL-6) e o fator de necrose tumoral (TNF) são as principais citocinas da imunidade inata. Seus principais efeitos se dão nas células endoteliais, nos leucócitos e nos fibroblastos, além de efeitos sistêmicos como febre e perda de apetite. As ILs 2, 4, 12 e 15 e o fator transformador de crescimento $\beta$ (TGF- $\beta$ ) são citocinas relacionadas com ativação e diferenciação dos linfócitos. Dentre as citocinas que ativam células inflamatórias estão a IL-5, o TNF e o interferon $Y$ (INF-Y) (36).

As quimiocinas são citocinas quimiotáticas, de pequeno peso molecular ( 8 a $10 \mathrm{kDa}$ ), que regulam a movimentação de leucócitos e controlam a migração celular fisiológica em vários tecidos. São importantes mediadores durante a organogênese, circulação e direcionamento de linfócitos através dos órgãos linfoides. Recentemente esses mediadores têm sido cada vez mais relacionados com a imunidade tumoral, potencial metastático e disseminação órgão específica (37). De acordo com a localização dos dois primeiros resíduos de cisteína $\mathrm{N}$-terminais, as quimiocinas são classificadas em quatro grupos: CXC, onde um aminoácido separa as duas primeiras cisteínas; $\mathrm{CC}$, onde dois resíduos conservados de cisteína encontram-se adjacentes; $\mathrm{C}$, onde só existe uma cisteína $\mathrm{N}$-terminal e $\mathrm{CX}_{3} \mathrm{C}$, onde existem três aminoácidos não conservados separando um par de cisteínas.

A ação dessas proteínas depende de sua ligação com receptores transmembrana, que por sua vez estão ligados à proteína $\mathrm{G}$. A classificação desses receptores depende do tipo de ligante: CXC liga-se a receptores CXCR, CC a receptores CCR e assim por diante. Esses receptores geralmente apresentam sobreposição de especificidade para seus ligantes. A célula que possui um receptor de quimiocina vai migrar em direção ao grandiente crescente de concentração do ligante. Os dois maiores grupos de quimiocinas são o CXC e o CC. Quimiocinas CXC são as que estão mais envolvidas com a migração de neutrófilos e linfócitos. Seus indutores mais importantes são produtos bacterianos, IL-1 e TNF. A quimiocina CXCL8 (IL-8) é um importante membro deste grupo e pode ligar-se tanto a CXCR1 quanto a CXCR2. As moléculas do segundo grupo exercem quimiotaxia para monócitos, eosinófilos, basófilos e linfócitos, mas não para neutrófilos $(2,38)$. 
O equilíbrio entre citocinas pró e anti-inflamatórias é essencial para o controle das respostas imunes e proteção contra o dano tecidual e desenvolvimento de doenças como as autoimunes e o câncer.

\subsection{Citocinas e câncer}

As citocinas inflamatórias são peças fundamentais nos processos que relacionam inflamação e câncer. Atualmente está claro que essas moléculas estão envolvidas em diferentes mecanismos da progressão tumoral como proliferação, apoptose, infiltração leucocitária, evasão da resposta imune antitumoral, alteração da resposta a hormônios e agentes quimioterápicos, produção de metaloproteinases, angiogênese, invasão e metástase (39, 40). Acreditava-se que as citocinas inflamatórias presentes no microambiente neoplásico fossem produzidas somente pelas células inflamatórias, porém hoje sabe-se que as células neoplásicas também produzem e liberam essas moléculas.

Grande parte dos estudos sobre a relação de citocinas e desenvolvimento de câncer foi realizada em relação às doenças intestinais inflamatórias e o risco de desenvolvimento de câncer de cólon. As citocinas IL-6 e IL-8 estão presentes nos resultados de muitos desses estudos, sejam eles in vitro ou in vivo. Altas concentrações plasmáticas de IL-6 foram relacionadas a tumores maiores, metástase para o fígado e aumento do número de recorrências tumorais. Altos níveis de IL-8 relacionaram-se com pobre prognóstico dos pacientes com câncer de cólon (41, 42). Polimorfismos nos genes das interleucinas IL-3, IL-6, IL-8 e IL-15 foram relacionados com o aumento do risco de câncer de cólon. Já as alterações nos genes dos receptores, CXCR1 e CXCR2 foram significativamente associados ao aumento do risco de câncer retal (43). Em animais com câncer de cólon, a deficiência genética na produção da citocina IL-21, diminuiu a ativação das vias STAT, NF-KB e COX-2/PGE 2 tanto nas células imunes quanto nas células neoplásicas. Também ocorreu a diminuição na expressão de outras citocinas inflamatórias como a IL-6 e o TNF- $\alpha$, e diminuição da angiogênese (44). Em outro modelo de câncer de cólon observou-se aumento da expressão das citocinas IL-1 $1 \beta$ e IL-2. A primeira pode ativar o fator de transcrição NF-KB que por sua vez atua na 
transcrição de mais citocinas pró-inflamatórias. A IL-2 ativa os fatores Jak3 e Stat3 que são anti- apoptóticos (45).

Em câncer de pulmão o aumento da expressão de CXCL5 e CXCL8 correlacionou-se positivamente com progressão tumoral, angiogênese e ocorrência de metástases $(14,46)$. Em câncer de mama, as interleucinas IL-6 e IL-8 estão associadas com pobre prognóstico $(47,48)$.

A complexa rede de citocinas liberadas pelas células tumorais e células do microambiente tumoral influencia a quantidade e qualidade do infiltrado de células imunes presentes no tumor (49). As quimiocinas CXCL9 e CXCL10 mostraram ser importantes para os mecanismos de resposta antitumoral em câncer de mama (15). Em um subtipo específico de câncer de mama, o câncer de mama inflamatório (50), existe aumento na produção das citocinas IL-6, IL-8, CCL2 e CCL5. Esses mediadores relacionaram-se com o potencial de proliferação, migração e metástase das células tumorais $(37,51,52)$.

Estudos mostraram que a CXCL8 ou IL-8 tem uma importante função no crescimento e desenvolvimento de tumores sob condições de hipóxia, através de sua contribuição para a angiogênese (53-58). Elevados níveis de IL-8 têm sido relacionados com o aumento do potencial metastático em tumor gástrico (59), renal (60), ovariano (61) e colorretal (62). O aumento da expressão tanto de IL-6 quanto de IL-8 tem sido descrito em formas altamente agressivas de câncer $(63,64)$.

O processo de metástase, em vários de seus passos, assemelha-se com 0 tráfego de linfócitos para os linfonodos e órgão linfoides secundários. Muitas células neoplásicas passam a expressar receptores de quimiocinas em sua superfície e assim usam o mecanismo de quimiotaxia para viabilizar sua migração para linfonodos regionais ou sítios distantes do tumor original (2). Em melanomas, câncer gástrico, esofágico, de mama e carcinoma epidermoide de cabeça e pescoço foi encontrado aumento de expressão do receptor de quimiocina CCR7 e associação deste com metástases linfonodais (65-68). O receptor CXCR2 que pode ter como ligantes as quimiocinas CXCL1, CXCL2, CXCL3, CXCL5, CXCL6, CXCL7 e CXCL8 também foi relacionado a invasividade e metástases de câncer de pulmão, cólon e pancreático (69-71). 


\subsection{Citocinas e CEO}

Mais de $90 \%$ das neoplasias malignas que acometem a cavidade oral são representadas pelo carcinoma epidermoide, por isso essa patologia tornou-se praticamente sinônimo de câncer de boca. $O$ diagnóstico geralmente tardio e a falta de terapias eficientes são as duas principais causas da grande morbidade relacionada a essa neoplasia. A principal terapia, remoção cirúrgica da lesão, gera problemas fisiológicos e psicossociais importantes. Altas taxas de recorrência e de disseminação nodal conferem a essa neoplasia um prognóstico sombrio. Há várias décadas o CEO tem representado grande desafio da saúde pública em muitos países em desenvolvimento, inclusive no Brasil. De acordo com o Instituto Nacional de Câncer (4), foram estimados, para 2014, cerca de 11.280 novos casos de câncer da cavidade oral em homens e $4.010 \mathrm{em}$ mulheres, sendo a maior parte dos casos estimada para a região sudeste. Assim, nesta região, este tipo de câncer representa o $4^{0}$ tipo mais frequente em homens, ficando atrás somente das neoplasias de próstata, cólon e pulmão.

Assim como em outros tipos de neoplasia, as citocinas e fatores de transcrição têm mostrado grande relevância na relação entre inflamação e câncer de boca.

Pacientes com CEO frequentemente apresentam níveis elevados de IL-6 na saliva e no sangue quando comparados aos pacientes controle $(5,72-79)$ e pacientes com leucoplasia (77). Tem sido mostrado que as células do CEO preferencialmente invadem e metastatizam em ambientes ricos em IL-6 (80), altos níveis dessa citocina também têm sido associados à recorrência, invasão de linfonodos e pobre prognóstico (80-83). O processo inflamatório induzido por IL-6, em linhagens celulares de CEO, também mostrou importante participação no controle da expressão gênica através de alterações epigenéticas, como a hipermetilação de genes supressores de tumor $(84,85)$.

O TNF- a é uma citocina que estimula a expressão de moléculas de adesão, como as selectinas e os ligantes de integrinas, pelas células endoteliais; a secreção de quimiocinas por células endoteliais e macrófago e a morte celular apoptótica através da ativação de caspases. O TNF- $\alpha$ ativa o regulador do ciclo celular NF-KB, o que leva à evasão da apoptose e a proliferação celular (86). Essa citocina também 
pode atuar como um potente agente mutagênico endógeno causando danos diretos ao DNA através da indução de espécies reativas do oxigênio. Pacientes com CEO e lesões orais pré-cancerizáveis apresentam elevados níveis salivares e plasmáticos de TNF- $\alpha$ e IL-1 $\beta$ quando comparados aqueles de indivíduos saudáveis $(72,73,75$ $78,87,88)$. Elevados níveis plasmáticos de TNF- a foram também relacionados com a diminuição da sobrevida de pacientes com câncer de cabeça e pescoço (89).

A capacidade de invasividade das células malignas pode aumentar na presença de algumas citocinas inflamatórias como TNF- $\alpha, \mathrm{IL}-1 \beta$ e IL-6, possivelmente como resultado da superexpressão de receptores de quimiocina promovida por essas citocinas (90). Em cultura de células de CEO a IL-1 $\beta$ foi um potente indutor de CXCL8 e CXCL10 (91). Rentoft et al. (2014) (92) mostraram que a eficiência do tratamento radioterápico teve relação direta com o aumento de sobrevida de pacientes com CEO de língua. No entanto, pacientes cujos tecidos tumorais apresentaram expressão mais elevada da quimiocina CXCL10 mostraram uma pior resposta a esse tipo de tratamento.

Os níveis das quimiocinas IL-8, CCL5 e CXCL10 foram significativamente mais altos nas culturas e amostras teciduais de CEO do que em cultura de queratinócitos normais. A proliferação e a viabilidade das células neoplásicas foram marcadamente diminuídas quando um RNA de interferência foi utilizado para diminuir o nível de IL-8 nessas culturas. A cascata de sinalização da IL-8 pode ser um importante ponto de falha na regulação gênica, associando inflamação e CEO (6). A alta expressão desta quimiocina em células de CEO foi observada pela primeira vez em 1995 (93), nos anos seguintes as pesquisas mostraram que essas citocina está relacionada à proliferação, migração, invasão e angiogênese deste tipo de neoplasia $(7,94,95)$. E ainda, pacientes com CEO apresentam níveis salivares de IL-8 mais altos do que aqueles encontrados em indivíduos sem a doença (96).

As lesões de CEO apresentam alta taxa de metástases linfonodais, esse fator é um importante determinante de prognóstico ruim dos pacientes. Cerca de $90 \%$ de pacientes que não apresentam metástase vão apresentar uma sobrevida de 5 anos. Essa porcentagem cai para $40 \%$ em casos de pacientes com metástase. Ainda não se conhece, em profundidade, os mecanismos responsáveis pelas características de invasão e metástase do CEO. Em meio a vários mediadores, muitas citocinas inflamatórias e seus receptores parecem estar envolvidos nesses mecanismos (97). O eixo CCL5/CCR5 mostrou estar envolvido no aumento do potencial de migração 
celular e aumento da expressão de MMP-9 por linhagens celulares de CEO (98). A expressão, pelas células neoplásicas, do receptor de quimiocina CCR7 mostrou relação positiva com a ocorrência de metástases para linfonodos cervicais em pacientes de CEO $(99,100)$. Essa relação também foi encontrada, em estudo recente, para o receptor CXCR2. Também foram realizados estudos in vitro onde, através do silenciamento de CXCR2 e consequente reorganização do citoesqueleto celular, foi possível inibir a capacidade de migração e invasão das células de CEO (101). A ligação de alta afinidade de CXCR1 e CXCR2 com a quimiocina IL-8 mostrou importante efeito no aumento da proliferação, migração, invasão e produção de metaloproteinases por linhagens celulares de CEO (7). Um estudo de 2010 mostrou que um antagonista de CXCR2 inibiu a viabilidade de células de CEO. Em estudo in vivo, o mesmo trabalho sugeriu a relação positiva entre o aumento da expressão deste receptor de quimiocina com o aumento de VEGF, importante fator angiogênico, e caspase-3, importante enzima para o mecanismo de apoptose (102).

\subsection{Anti-inflamatórios não esteroides (AINEs)}

Os AINEs são um grupo de fármacos de estrutura química variada que têm como atividades a modulação da inflamação, a analgesia e o controle da hipertermia. Essas substâncias atuam na inibição de enzimas do grupo das ciclooxigenases, impedindo assim a síntese de eicosanoides através da via metabólica do ácido araquidônico. Existem três formas de COXs, a COX-1 é considerada a isoforma constitutiva, uma vez que é produzida em níveis elevados, por vários tipos celulares, em condições de normalidade. Sua ativação leva à produção de prostaciclinas e PGs que mostram ação antitrombogênica, de proteção da mucosa gástrica e manutenção do fluxo sanguíneo nos rins. A COX-3 é considerada um tipo de COX-1 produzida no tecido nervoso. A COX-2, embora também seja produzida de maneira constitutiva por alguns tipos celulares, tem sua produção aumentada em até 80 vezes após estímulo inflamatório. Quando da sua descoberta, foi chamada de isoforma induzível ou inflamatória. As COXs 1 e 2 apresentam $60 \%$ de homologia e o sítio de ligação com o ácido aracdônico é 
formado por um canal longo e estreito, que ao final apresenta uma dobra, com o formato de um grampo de cabelo. Uma diferença muito importante entre essas enzimas está na posição 523, onde a COX-1 apresenta uma isoleucina e a COX-2 uma valina. Essa alteração permite que o canal de encaixe do ácido aracdônico na COX-2 seja 17\% mais largo do que o da COX-1. O ácido aracdônico proveniente de membranas plasmáticas lesionadas entra nesse canal onde é oxigenado e dá origem às prostaglandinas. Os AINEs impendem a entrada do ácido aracdônico nesses canais, consequentemente inibem a produção de PGs, responsáveis pelos sinais e sintomas da inflamação $(10,11)$. Estudos têm mostrado que o uso prolongado de alguns AINEs pode estar relacionado com a prevenção de doenças cardíacas agudas, doença de Alzheimer e neoplasias (103).

\subsection{1 Ácido acetilsalicílico (AAS)}

O emprego de salicilatos no alívio da dor é bastante antigo. Presentes em papiros do antigo Egito estão orientações da aplicação do produto da decocção das folhas de murta para alívio das dores reumáticas. Mil anos mais tarde, Hipócrates recomendava o uso do sulco da casca do salgueiro para reduzir a febre. Celsus, 30 anos A.C, também usava os extratos destas folhas para aliviar os quatro sinais clássicos da inflamação (calor, rubor tumor e dor). O uso terapêutico dos salicilatos presentes nas plantas desenvolveu-se também na Roma antiga de Galeno, China, África do Sul e América do Norte (10). O primeiro estudo clínico utilizando as propriedades terapêuticas da casca do salgueiro foi publicado na Inglaterra, em 1763, pelo Reverendo Edward Stone (104). O ácido salicílico foi sintetizado pela primeira vez em 1859, na Alemanha. Em 1899, o diretor de pesquisas da Bayer, Heinrich Dreser, publicou um artigo onde apresentava a Aspirina (ácido acetilsalicílico) como uma maneira de suprir o organismo com salicilatos (105). A formulação da Aspirina, no entanto, é mérito de Felix Hoffman, químico da Bayer, que produziu um salicilato mais palatável para ser usado pelos pacientes (10).

O ácido acetilsalicílico AAS é o mais antigo e o mais conhecido dos AINEs. Este fármaco inibe, de maneira irreversível, a atividade das enzimas COX-1 e COX-2 
através de uma reação de acetilação com um resíduo serina, presente no canal de ligação da enzima com o ácido aracdônico $(106,107)$. Assim, tanto o AAS quanto várias outras drogas chamadas de "aspirin-like" inibem ambas as formas de COXs. Consequentemente, a produção das chamadas prostaglandinas constitutivas também é inibida e efeitos colaterais importantes como dano à mucosa gástrica, toxicidade hepática e inibição da agregação plaquetária podem surgir durante o uso desses fármacos (108).

\subsubsection{Celecoxibe (CLX)}

Vários estudos in vitro e in vivo, realizados no final dos anos 80 , mostraram um aumento da expressão de COX-2 durante a inflamação (11). Essas evidências, combinadas com a aquisição do conhecimento sobre a estrutura química e as funções das COXs $(109,110)$ e com o desejo de desenvolver AINEs que não possuíssem os efeitos colaterais do AAS e das drogas "aspirin-like", proporcionaram o direcionamento dos esforços para criar fármacos que fossem inibidores específicos de COX-2. Em 1998 o primeiro do grupo foi introduzido na prática clínica, o celecoxibe (Celebrex®) (111). Os estudos haviam mostrado que o fármaco apresentara efeitos anti-inflamatórios semelhantes aos de outros AINEs e menos efeitos gastointestinais (112). Assim como outros inibidores específicos de COX-2, a especificidade do celecoxibe se dá por conta da diferença de tamanho do canal que forma o sítio ativo das COXs. Como este canal é mais largo na COX-2, os AINEs que bloqueiam COX-2 não se encaixam no sítio da COX-1 e desta maneira não inibem está última, consequentemente as prostaglandinas constitutivas (11). 


\subsection{AAS, CLX e câncer}

O primeiro estudo a considerar a hipóstese de envolvimento das COXs na carcinogênese foi realizado em 1976. Os pesquisadores mostraram, in vitro, qua o AAS foi capaz de inibir a atividade osteolítica de células de tumores de mama (12). Nas décadas seguintes acumularam-se trabalhos mostrando o aumento da expressão das COXs em vários tipos de tumores. A presença de grande quantidade dessas enzimas nos tecidos neoplásicos já foi relacionada ao aumento de proliferação celular, maior poder de invasividade e pior prognóstico (103).

O estudo de Kune et al. de 1988 (13) foi o primeiro a mostrar o papel preventivo do AAS no carcinoma de cólon. Na década de 90 muitos outros trabalhos foram publicados confirmando que este anti-inflamatório era capaz de reduzir o risco de desenvolvimento de câncer colorretal $(113,114)$. Ainda na década de 90 ficou claro que a COX-2 era muito mais expressa por células do câncer colorretal do que a $\operatorname{COX}-1(115,116)$. O aumento de expressão dessa enzima leva à diminuição da apoptose, aumento da adesão das células com a matriz e aumento de expressão de Bcl-2 (117). Pesquisas posteriores mostraram que tanto a deleção do gene da COX2 quanto o tratamento com inibidores específicos de COX-2 reduziram fortemente 0 desenvolvimento de polipose intestinal em ratos com gene $A p c$ mutante $(118,119)$. Observou-se que o CLX é capaz de reduzir o número de pólipos colorretais em indivíduos com polipose adenomatosa familiar (PAF), inclusive em pacientes pediátricos (120-122), e atualmente é tratamento padrão indicado pré e pós colectomia (123). Dentre as atividades antineoplásicas do CLX estão a capacidade de inibir ou reduzir a proliferação celular e induzir as células neoplásicas à apoptose. Os mecanismos pelos quais esses efeitos são atingidos podem ser tanto COX dependente como independente. De fato, nem toda atividade anti-tumoral dos AINEs é atribuída à inibição de COXs. Existem estudos mostrando efeitos independentes de COXs relacionados à inibição do desenvolvimento / crescimento tumoral (124). 
O tratamento de linhagens celulares de CEO com AAS e CLX mostrou ser capaz de diminuir a proliferação e a capacidade de migração/invasão dessas células assim como induzir-las à apoptose $(6,125-127)$. Mecanismos relacionados com o aumento da expressão da proteína p27 e de MMPs parecem também estar envolvidos com a capacidade antineoplásica do $\operatorname{CLX}(125,127)$.

Drogas anti-inflamatórias podem reduzir o risco de alguns tipos de câncer por afetar a produção de citocinas inflamatórias e fatores de transcrição relacionados à inflamação. Meyer et al. (2011) (128) mostraram que tanto o AAS quanto o CLX foram capazes de diminuir a expressão das citocinas IL-6 e IL-8 por células de câncer de cabeça e pescoço, como consequência da inibição de NF-KB (128). Estudo clínico recente, com pacientes com câncer colorretal, revelou que o uso de CLX, durante um mês, causou alteração na expressão dos genes inflamatórios CXCL8 e CXCL14 (129).

Tanto o AAS quanto o CLX foram capazes de diminuir os níveis de IL-8 em células de câncer de pulmão (130). O uso de CLX diminuiu os níveis das citocinas pró-inflamatórias IL-1 $\beta$ e IL-2 em um estudo de câncer de cólon em animais. A expressão dos fatores de transcrição antiapoptóticos Jak3 e Stat3, que são ativados por IL-2, também diminuiu. Neste mesmo trabalho o tratamento com CLX foi capaz de aumentar a expressão de IL-4, essa citocina parece ter um efeito inibitório em neoplasias humanas. Assim, os autores relataram que o efeito anti-neoplásico dos AINEs pode estar relacionado com o aumento de expressão dessa citocina (45). Em outra pesquisa, o uso de CLX em cultura de células de carcinoma hepatocelular diminuiu a sinalização na via da IL-6/STAT3 inibindo, dessa forma, a resistência das células às drogas anti neoplásicas (131).

O tratamento com AAS foi importante para aumentar a liberação de CXCL10 e CXCL9 por células de carcinoma mamário. Diminuindo a produção de PGs foi possível aumentar os níveis dessas citocinas relacionadas com atividade imune antitumoral (15). Bergman et al. (2011) constataram que os efeitos antineoplásicos do AAS também podem estar relacionados com a alteração da produção e liberação de citocinas pró e anti-inflamatórias por células neoplásicas e células do sistema imunológico, alterando a sinalização entre elas. Os autores encontraram diferenças na produção de citocinas por monócitos estimulados por células de câncer de cólon quando tratadas ou não com AAS (132). 


\section{PROPOSIÇÃO}

Avaliar a expressão de citocinas inflamatórias em linhagens celulares de carcinoma epidermoide de boca após tratamento com os anti-inflamatórios ácido acetilsalicílico e celecoxibe. 


\section{MATERIAL E MÉTODOS}

Este estudo foi aprovado pelo Comitê de Ética da FOUSP - Parecer ํo 224.084 (Anexo A).

\subsection{Linhagens celulares}

As linhagens celulares de carcinoma epidermoide de boca - squamous cell carcinoma (SCC4, SCC9, SCC25), provenientes da American Type Culture Colection (ATCC, Manassas, VA, EUA), foram cultivadas em frascos plásticos de 75 $\mathrm{cm}^{2}$ e placas de 60 ou $100 \mathrm{~mm}$ (NUNC, Naperville, IL, EUA) em meio de cultivo RPMI 1640 (Invitrogen, Carlsbad, CA, EUA) suplementado com 10\% de soro fetal bovino (SFB) (Invitrogen), 1\% de L-glutamina e 1\% de solução antimicótica e antibiótica (Sigma-Aldrich St Louis, MO, EUA) e mantidas a $37^{\circ} \mathrm{C}$ em atmosfera contendo $5 \%$ de $\mathrm{CO}^{2}$ e $95 \%$ de umidade até que atingissem confluência de 70-80\%. O meio de cultivo foi trocado a cada dois ou três dias, de acordo com o metabolismo celular.

\subsection{Tratamento das linhagens com anti-inflamatórios}

4.2.1 Ácido acetilsalicílico (AAS)

A partir de uma solução de estoque de $1000 \mathrm{mM}$ de AAS (Aspirin - SigmaAldrich, St Louis, MO, EUA) dissolvido em etanol absoluto (Vetec, Caxias do Sul, RJ, Brasil) foram preparadas as soluções de tratamento em meio de cultivo RPMI 
suplementado. Para controle foram preparadas soluções com as mesmas quantidades de etanol usadas nas soluções de tratamento.

\subsubsection{Celecoxibe}

Foi preparada uma solução de estoque de $100 \mathrm{mM}$ de celecoxibe (Pfizer, New York, NY EUA) em dimetilsulfóxido DMSO (Sigma- Aldrich). No momento do preparo das soluções de tratamento a solução de estoque foi diluída em meio RPMI suplementado. Para controle foram preparadas soluções com as mesmas quantidades de DMSO usadas nas soluções de tratamento.

\subsection{Ensaio imunoenzimático para IL-6 (ELISA)}

Este experimento foi realizado com o objetivo de observar em qual concentração e tempo de tratamento mínimos, os fármacos aqui empregados modificavam a quantidade de IL-6 produzida pela linhagem SCC9. A escolha da linhagem e citocina utilizada foi baseada em estudo prévio, através de ensaio imunoenzimático usando-se o sistema Luminex® хMAPTM, que mostrou alta expressão de IL-6 por células da linhagem SCC9 (dado não mostrado). Foi utilizado o Human IL-6 ELISA Kit (Novex ${ }^{\text {TM }}$, Life Technologies, EUA). O experimento foi feito com $100 \mu \mathrm{L}$ do sobrenadante das amostras de SCC9 tratadas com AAS (1, 3 e 6mM) e $\operatorname{CLX}(1,3$ e $6 \mu \mathrm{M})$ nos tempos de 1, 6 e 12 horas. Também foram testadas as amostras cultivadas com etanol (controle do AAS), DMSO (controle do CLX) e somente com o meio de cultivo. As concentrações para este experimento foram determinadas com base nas concentrações plasmáticas em humanos, quando os fármacos são utilizados como anti-inflamatórios $(133,134)$. As concentrações finais de etanol variaram de 0,1 à $0,6 \%$ e de DMSO de 0,01 à $0,06 \%$. Todas as condições de concentração e tratamento foram feitas em triplicata e as etapas do experimento seguiram as recomendações do fabricante. 


\subsection{Ensaio de viabilidade celular}

Com o objetivo de analisar a toxicidade dos fármacos utilizados neste estudo foi realizado um ensaio de viabilidade celular. $A$ análise da toxicidade dos fármacos foi feita através da curva dose dependente de viabilidade celular, utilizando-se o MTT (brometo de 3-[4,5-dimetil-tiazol-2-il]-2,5-difeniltetrazólio) (CellTiter 96® AQueous One Solution Cell Proliferation Assay - Promega, Madison, Wiscosin, EUA). $O$ experimento foi realizado em quadruplicata, para todas as linhagens, em placas de 96 poços. Em cada poço foram cultivadas $5 \times 10^{3}$ células em $100 \mu$ de meio por 24 horas. Posteriormente as células receberam três banhos de PBS $1 \mathrm{X} \mathrm{e}$ foi adicionado meio sem soro, dessa maneira as células permaneceram em starvation por 24 horas. Em seguida, foi acrescentado novamente meio com soro por 12 horas. As células receberam então as mesmas soluções de tratamento usadas no ensaio imunoenzimático descrito anteriormente. Após o tratamento foi adicionado o MTT em cada poço (20 $\mu$ l de MTT para cada $100 \mu$ de meio de cultura) e as placas foram protegidas da luz com papel alumínio e mantidas em estufa de $\mathrm{CO}_{2}$ à $37^{\circ} \mathrm{C}$ por 240 minutos. As leituras foram feitas nos tempos de 1,6 e 12 horas em espectofotômetro (ELX 800 Bio-Tek instruments Inc.) com filtro de $490 \mathrm{~nm}$.

\subsection{Obtenção do RNA total}

As células foram lavadas com PBS 1X gelado e incubadas com 1,5 ml de TRIzol (Invitrogen) por cinco minutos. Posteriormente as células foram despregadas pela raspagem da placa com a parte de trás de uma ponteira de $1 \mathrm{ml}$, e coletadas em tubos de polipropileno livres de DNAse e RNAse. Para cada 1,5 ml de TRIzol de células coletadas foram adicionados $300 \mu \mathrm{l}$ de clorofórmio P.A gelado. Os tubos foram agitados vigorosamente por 15 segundos e ficaram por três minutos em temperatura ambiente (TA). Posteriormente foi feita a centrifugação dos tubos a $10.200 \mathrm{xg}$, durante 15 minutos a $4^{\circ} \mathrm{C}$. A fase aquosa foi removida cuidadosamente e transferida para um novo tubo que recebeu $750 \mu \mathrm{l}$ de isopropanol P.A gelado, 
permanecendo em TA por 10 minutos. Foi realizada nova centrifugação, agora a $10.200 \mathrm{xg}$ por 10 minutos a $4^{\circ} \mathrm{C}$. Neste momento foi possível observar a formação de precipitado de RNA no fundo do tubo. O sobrenadante foi descartado e $1 \mathrm{ml}$ de etanol $70 \%$ gelado foi lentamente adicionado ao precipitado de cada tubo. Os tubos foram novamente levados à centrífuga a $8.400 \mathrm{xg}$ por cinco minutos a $4^{\circ} \mathrm{C}$. O etanol foi descartado e os tubos permaneceram abertos, em TA, para que o restante do etanol evaporasse. O precipitado foi ressuspenso em $20 \mu$ de água livre de DNAse e RNAse. A concentração e a pureza do RNA foram determinadas em espectrofotômetro (NANODROP 2000 - Thermo Scientific), com comprimento de onda de 260 a $280 \mathrm{~nm}$. Os tubos foram armazenados a $-80^{\circ} \mathrm{C}$.

\subsection{PCR array}

Todas as amostras foram submetidas a reação de RT-qPCR para o gene $\beta$ actina, utilizado com controle endógeno, para avaliar a qualidade das amostras.

Para confecção do cDNA para as reações de PCR Array foram utilizados os reagentes do $\mathrm{RT}^{2}$ First Strand Kit (QIAGEN), para $1 \mu \mathrm{g}$ de RNA. Para análise da expressão gênica foi utilizado o sistema $\mathrm{RT}^{2}$ Profiler PCR Array PAHS-022ZA (QIAGEN) com placas de 96 poços contendo pares de primers liofilizados de genes de 84 citocinas, quimiocinas e receptores de quimiocinas, além de cinco diferentes genes de controle endógenos, um controle de contaminação por DNA genômico, controle da transcriptase reversa e controle positivo da reação de PCR. O desenho da placa utilizada neste experimento encontra-se no anexo B. Para cada reação foram utilizados $1.350 \mu \mathrm{l}$ de $\mathrm{RT}^{2}$ SYBR Green ROX ${ }^{\mathrm{TM}}$ qPCR Mastermix (QIAGEN), $102 \mu \mathrm{l}$ de cDNA e $1.248 \mu \mathrm{l}$ de água livre de RNAse. Em cada um dos 96 poços da placa foram adicionados $25 \mu \mathrm{l}$ desta solução. Em seguida as placas eram levadas para termociclador 7.500 Real-Time PCR System (Applied Biosystesms Calsbad, CA, EUA) onde eram submetidas a um ciclo de 10 minutos a $95^{\circ} \mathrm{C}, 40$ ciclos de 15 minutos a $95^{\circ} \mathrm{C}$ e 1 minuto a $60^{\circ} \mathrm{C}$ (Tabela 4.1). 
Tabela 4.1 - Relação dos ciclos dos experimentos de PCR array

\begin{tabular}{cccc} 
& Ciclos & Tempo & Temperatura \\
\cline { 2 - 4 } Termociclador & 1 & 10 minutos & $95^{\circ} \mathrm{C}$ \\
\cline { 2 - 4 } 7500 Real Time PCR System & 40 & 15 minutos & $95^{\circ} \mathrm{C}$ \\
\cline { 2 - 3 } Applied Biosystems & & & $60^{\circ} \mathrm{C}$
\end{tabular}

Os cálculos da expressão diferencial entre as amostras tratadas e controles foram realizados através do software RT2 Profiler PCR Array Data Analysis version 3.5, fornecido pela próprio fabricante das placas, através do site www.SABiosciences.com/pcrarraydataanalysis.php. A normalização foi feita de acordo com a média geométrica dos cinco genes de controle endógeno. A quantificação relativa da expressão gênica da amostra tratada em relação à amostra controle foi realizada pelo método $2^{-\Delta \Delta C T}$.

\subsection{Análise dos dados e estatística}

Para análise estatística dos dados foi usado o software GraphPad Prism 6 (GraphPad Software Inc, La Jolla, CA, EUA). No ensaio de viabilidade celular foi feita normalização dos dados para que os valores de absorbância pudessem ser escritos como porcentagem de células viáveis. Posteriormente foi utilizado o teste de análise de variância Two way ANOVA seguido pelo teste t de Tukey. Para análise dos valores de expressão de IL-6 no ensaio ELISA também foi usado o teste Two way ANOVA, seguido do teste de Sidak. Em todas as análises, $p \leq 0,05$ foi considerado como indicativo de diferença estatística significante. 


\section{RESULTADOS}

\subsection{O tratamento com AAS diminuiu e com CLX aumentou a expressão proteica de IL-6 por células da linhagem SCC9.}

De acordo com a figura 5.1 foi observado que a solução de AAS diminuiu a produção de IL-6 em todas as três concentrações nos tempos de 6 e 12 horas. No entanto, a solução de etanol, por si só, foi capaz de modificar a produção de IL-6 nas concentrações relativas de 1,3 e $6 \mathrm{mM}$ em 6 horas e $6 \mathrm{mM}$ em 12 horas. Dessa forma, a concentração e tempo escolhidos para tratamento com AAS, foram de $3 \mathrm{mM}$ por 12 horas.

Para tratamento com CLX foi selecionada a concentração de $6 \mathrm{mM}$ por 6 horas (Figura 5.2).
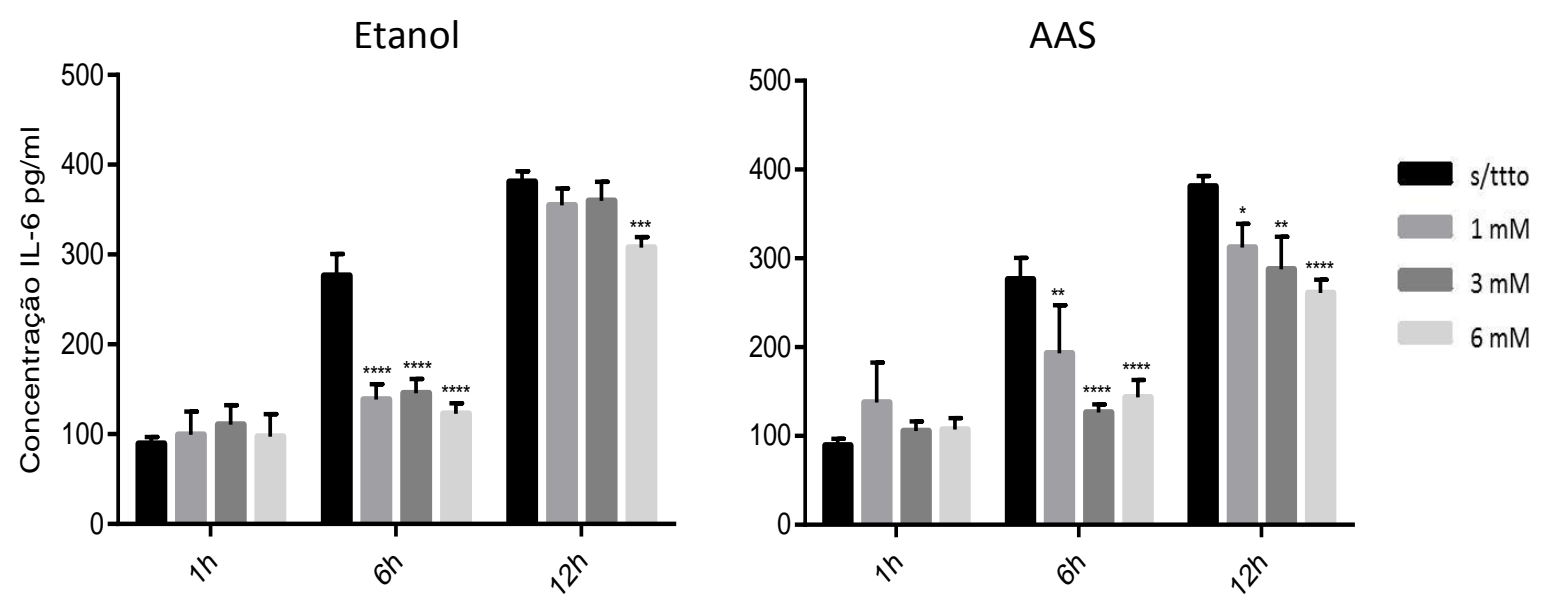

Figura 5.1 - Representação gráfica da concentração de IL-6, na linhagem SCC9, após tratamento com etanol ou AAS. Os asteriscos representam as diferenças estatísticas entre o grupo marcado e o grupo sem tratamento (s/ttto) para cada tempo. ${ }^{*} \mathrm{p}=0,0234 ;{ }^{* *} \mathrm{p}=0,0030 ;{ }^{* \star *} \mathrm{p}=0,0002 ;{ }^{* * * *} \mathrm{p}<0,0001$ 

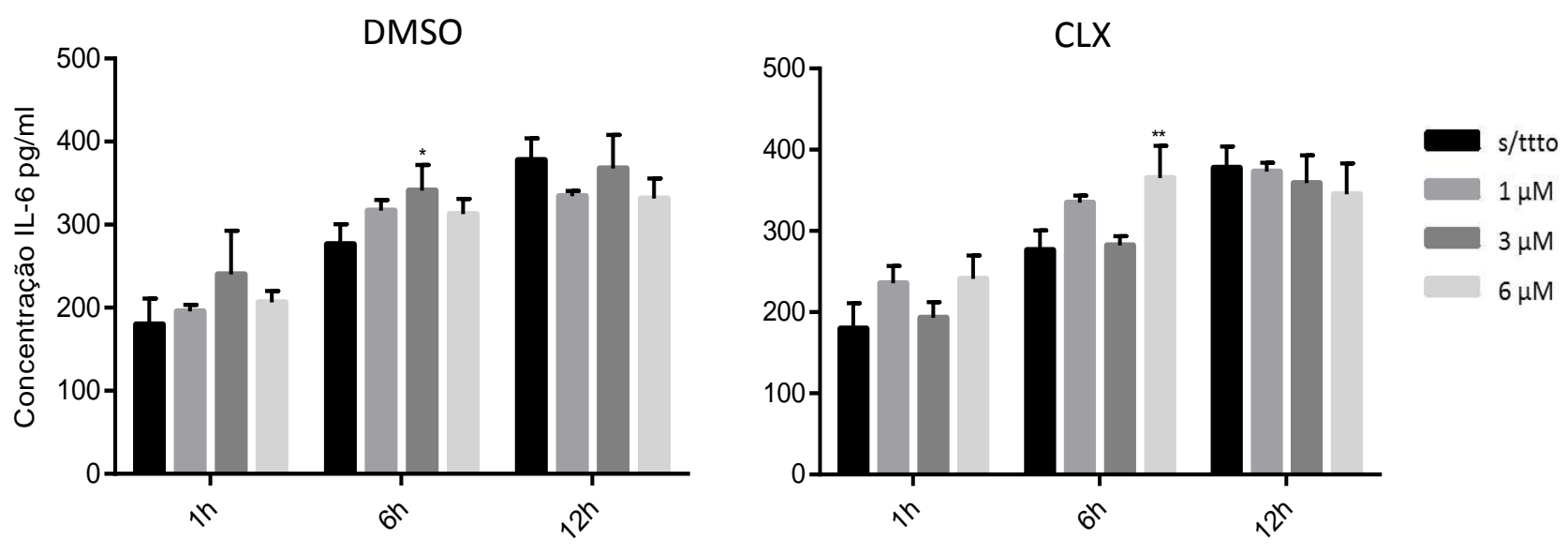

Figura 5.2 - Representação gráfica da concentração de IL-6, na linhagem SCC9, após tratamento com DMSO ou CLX. Os asteriscos representam as diferenças estatísticas entre o grupo marcado e o grupo sem tratamento (s/ttto) para cada tempo. ${ }^{*} \mathrm{p}=0,0234 ;{ }^{* *} \mathrm{p}=0,0030$

\subsection{Os tratamentos com $3 \mathrm{mM}$ de AAS por 12 horas e $6 \mu \mathrm{M}$ de CLX por 6 horas não interferiram com a viabilidade celular das linhagens SCC4, SCC9 e SCC25.}

Este ensaio foi realizado com o objetivo de verificar se as concentrações dos fármacos e tempos de tratamento escolhidos no ensaio imunoenzimático apresentavam toxicidade para as células das linhagens estudadas. De acordo com o que se pode observar nas figuras 5.3 e 5.4, as condições de concentração e tempo de tratamento escolhidos, não interferiram com a viabilidade celular em nenhuma das três linhagens. 



Figura 5.3 - Representação gráfica da porcentagem de células viáveis, após tratamento com etanol ou AAS. As barras em preto representam as amostras que não receberam nenhum tratamento, esse grupo foi considerado como tendo 100\% de células viáveis. Os asteriscos representam as diferenças estatísticas entre o grupo marcado e o grupo sem tratamento, para cada tempo. ${ }^{* * *} \mathrm{p}<0,001$ 

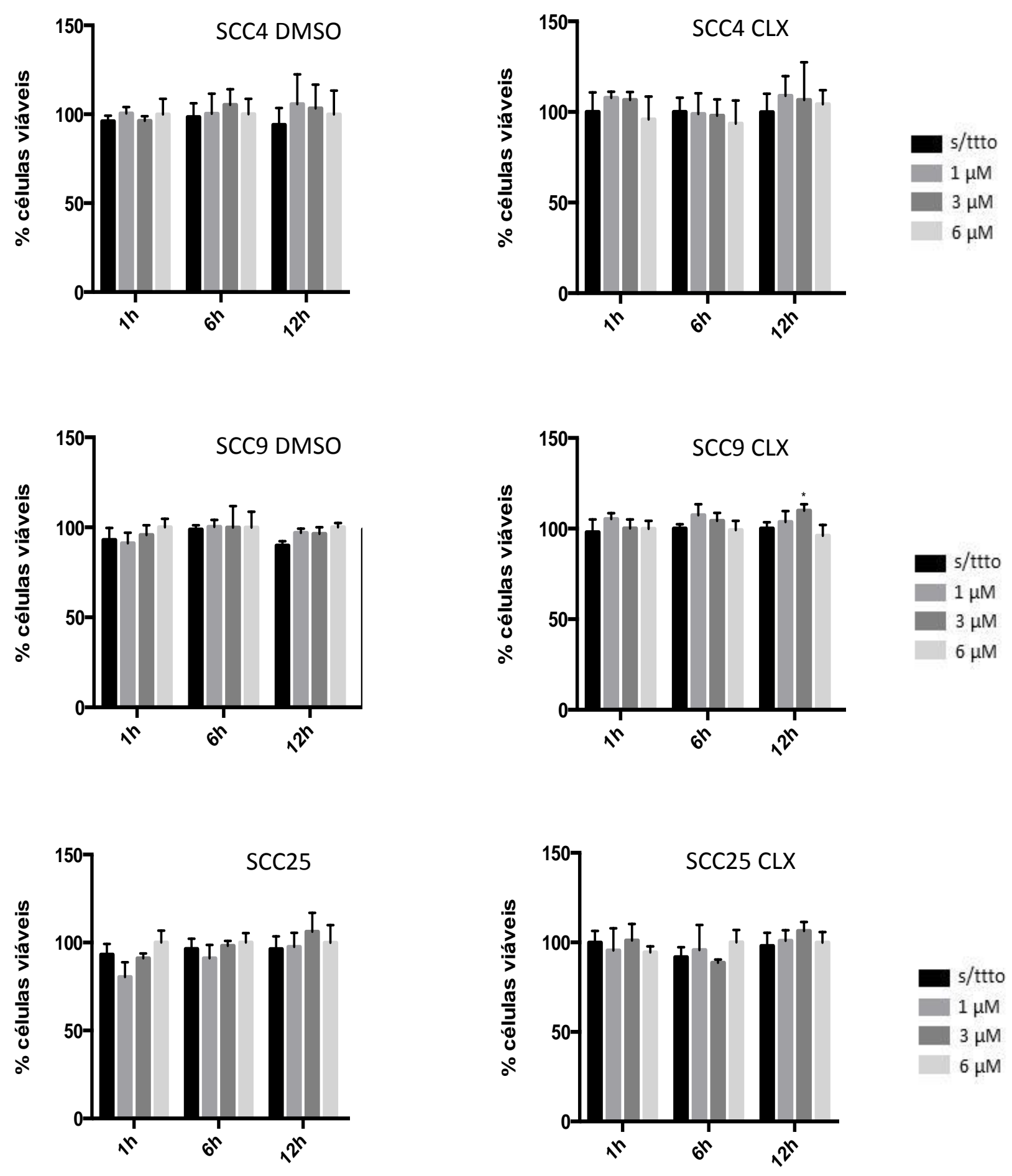

Figura 5.4 - Representação gráfica da porcentagem de células viáveis, após tratamento com DMSO ou CLX. As barras em preto representam as amostras que não receberam nenhum tratamento, esse grupo foi considerado como tendo $100 \%$ de células viáveis. Os asteriscos representam as diferenças estatísticas entre o grupo marcado e o grupo sem tratamento, para cada tempo. ${ }^{*} p<0,05$ 


\subsection{Os tratamentos com AAS e CLX modularam a expressão de citocinas inflamatórias nas três linhagens estudadas}

O resultado da expressão gênica diferencial dos grupos tratados (AAS e CLX) foi dado pelo número de vezes (fold regulation) em que os genes apresentaram aumento ou diminuição de expressão em relação ao respectivo grupo controle (Etanol ou DMSO). Foram considerados somente os genes que mostraram expressão diferencial com fold regulation $\geq 2.0$ ou $\leq-2.0$. Os genes para citocinas e receptores de citocinas que apresentaram expressão diferencial após o tratamento, para mais ou para menos, estão listados na figura 5.5 para o AAS, e na figura 5.6 para o CLX. Nas referidas figuras estão listados somente os genes que apresentaram, ou na amostra tratada ou na amostra controle ou em ambas, valor de $\mathrm{Ct}<30$. São as categorias "A" e "OKAY" dadas quando da análise dos dados pelo software.

Observa-se na figura 5.5 que o tratamento com AAS diminuiu a expressão dos genes ACKR4, CXCL10, CXCL11, CXCL3, CXCL6, IL8 e PF4V1 na linhagem SCC4. Na linhagem SCC9 esse tratamento também diminuiu a expressão de ACKR4 e CXCL10, porém aumentou a expressão de CCL20, CCL27, CCL28, CCL3, $C C L 4, I L 1 \beta$ e IL8. Com relação à linhagem SCC25, ocorreu aumento da expressão de CXCL3, IL1 $\beta$ e IL4.

O tratamento com CLX (Figura 5.6) diminuiu a expressão do gene PF4V1 na linhagem SCC4. Na SCC9 diminuiu a expressão de XCL2 e aumentou a expressão de CCL28, CXCL16, CXCL3, CXCR6, ACKR3, IL1 $\beta$ e TNF. Na SCC25, aumentou a expressão de CCL20, CXCL16, CXCL9 e XCL2.

No anexo $C$ encontram-se as tabelas com os resultados de expressão diferencial (fold regulation) dos genes das três linhagens e dos dois tratamentos analisados, inclusive genes que apresentaram $35>\mathrm{Ct}>30$ (categoria $\mathrm{B}$ ), mas que ainda assim tiveram sua expressão modificada pelos fármacos. 


\begin{tabular}{|c|c|c|}
\hline & Aumento de expressão & Diminuição de expressão \\
\hline $\operatorname{scc} 4$ & & $\begin{array}{l}\text { ACKR4, CXCL10, CXCL11, } \\
\text { CXCL3, CXCL6, IL8, PF4V1 }\end{array}$ \\
\hline scc9 & $\begin{array}{l}\text { CCL20, CCL27, CCL28, CCL3, } \\
\text { CCL4, IL1 } \beta \text {, IL8 }\end{array}$ & ACKR4, CXCL10 \\
\hline SCC25 & CXCL3, IL1 $\beta$, IL4 & \\
\hline
\end{tabular}

Figura 5.5 - Genes diferencialmente expressos por qPCR nas linhagens tratadas com AAS em relação ao controle (Etanol)

\begin{tabular}{|c|l|l|}
\hline & \multicolumn{1}{|c|}{ Aumento de expressão } & Diminuição de expressão \\
\hline scc4 & PF4V1 \\
\hline scc9 & $\begin{array}{l}\text { CCL28, CXCL16, CXCL3, } \\
\text { CXCR6, ACKR3, IL1 } \beta, \text { TNF }\end{array}$ & XCL2 \\
\hline SCC25 & $\begin{array}{l}\text { CCL20, CXCL16, CXCL9, } \\
\text { XCL2 }\end{array}$ & \\
\hline
\end{tabular}

Figura 5.6 - Genes diferencialmente expressos por qPCR nas linhagens tratadas com CLX em relação ao controle (DMSO) 


\section{DISCUSSÃO}

O presente trabalho mostrou que os AINEs AAS e CLX foram capazes de modular a expressão de mRNA de citocinas inflamatórias. Observou-se ainda que o comportamento das linhagens foi diferente com relação a essa expressão, tanto entre os tratamentos, quanto dentro do mesmo tratamento.

Estima-se que o processo inflamatório crônico seja responsável por um em cada quatro casos de câncer (16) e segundo Balkwill e Mantovani (2001) (1), a liberação de citocinas e fatores de crescimento pelas células neoplásicas e células do estroma tumoral, é a chave da relação entre inflamação e câncer. A ciência tem mostrado que o uso de AINEs para prevenir e tratar vários tipos de neoplasia tem ratificado a importância de se considerar os efeitos da inflamação na terapia antitumoral.

O CEO representa mais de $90 \%$ das neoplasias malignas que acometem a cavidade oral, por isso essa patologia já tornou-se praticamente sinônimo de câncer de boca. O diagnóstico geralmente tardio e a falta de terapias eficientes são as duas principais causas da grande morbidade relacionada a essa neoplasia. Há várias décadas o CEO tem representado grande desafio da saúde pública em muitos países em desenvolvimento, inclusive no Brasil.

Alguns aspectos da relação entre inflamação e CEO vêm sendo desvendados. Sabe-se, por exemplo, que algumas citocinas inflamatórias como IL$1 \beta$, IL-6, TNF e quimiocinas como a IL-8, CCL5 e CXCL10 representam um papel importante nessa relação $(6,128)$. Sabe-se também que o tratamento com alguns AINEs, que já mostraram efeitos antitumorais importantes em outros tipos de neoplasia, tem indicado possíveis associações terapêuticas também para a prevenção e tratamento do $\operatorname{CEO}(135,136)$. Apesar desses avanços, muito ainda precisa ser esclarecido sobre a possibilidade de encontrar, nas vias inflamatórias, aliados na luta contra o câncer de boca.

O presente trabalho se propôs a avaliar os efeitos de dois AINEs, AAS e CLX, na modulação da expressão de mRNA de citocinas inflamatórias em três linhagens celulares de CEO. 
Umas das principais preocupações neste estudo foi a de trabalhar com concentrações que fossem próximas às concentrações plasmáticas dos AINEs, como anti-inflamatórios, em humanos. Apesar dos fármacos, em um organismo vivo, estarem constantemente sujeitos à degradação metabólica, o uso de concentrações mais próximas das concentrações plasmáticas parece mais razoável no que se refere à aplicabilidade clínica de resultados obtidos in vitro. Meyer et al. (2011) (128) também colocam esse ponto em questionamento, para eles é bastante difícil determinar a verdadeira dose terapêutica tecidual. Stark et al. (137), realizaram estudo prévio para determinação das concentrações plasmáticas do AAS para estudar seus efeitos em células de câncer de cólon. Em pesquisa à literatura foram encontradas variações referentes às concentrações plasmáticas dos AINEs utilizados neste estudo. As concentrações pesquisadas foram aquelas responsáveis por efeitos anti-inflamatórios das drogas. Para o AAS essa variação foi de 1 a $5 \mathrm{mM}$ $(133,138,139)$ e para o CLX de 1 a $5 \mu \mathrm{M}(140,141)$.

Este estudo teve como objetivo verificar se os AINEs AAS e CLX eram capazes de modular a expressão de citocinas inflamatórias por linhagens celulares de CEO. Assim, antes de realizar o ensaio de viabilidade celular, foi realizado ensaio imunoenzimático (ELISA) para IL-6. A escolha da realização deste ensaio foi feita para que, dentro da faixa de concentração plasmática máxima dos fármacos, fosse possível escolher a concentração e tempo de tratamento mínimo necessário para mudar a expressão de IL-6 pelas células neoplásicas. A escolha da citocina IL-6 baseou-se em resultados de ensaio prévio, realizado através do sistema Luminex® XMAP ${ }^{\text {TM }}$, no qual a linhagem SCC9 mostrou alta expressão dessa citocina (dado não mostrado). As doses de $3 \mathrm{mM}$ de AAS, durante 12 horas e $6 \mu \mathrm{M}$ de CLX por 6 horas foram capazes de modular a expressão de IL-6, no primeiro caso para menos, no segundo para mais (Figuras 5.1 e 5.2). Por ser a IL-6 uma citocina pró-inflamatória, esperava-se que ambos os AINEs fossem capazes de diminuir sua expressão, assim como mostraram Meyer et al. (2011) (128), trabalhando com células de câncer de cabeça e pescoço. No entanto, apesar dos autores terem usado a concentração de $2 \mathrm{mM}$ de AAS, usaram $25 \mu \mathrm{M}$ de CLX, ou seja, quase cinco vezes a concentração de CLX usada no presente trabalho. O CLX, no que se refere à modulação de citocinas, por vezes tem mostrado efeito paradoxal quando usado em dossgens muito baixas ou muito altas (15). 
Para saber se as doses e tempos de tratamento, escolhidos no ensaio de ELISA, afetavam a viabilidade celular a ponto de prejudicar a análise de produção de citocinas, foi realizado ensaio de viabilidade celular (MTT) para as três linhagens. As doses e tempos de tratamento escolhidos não interferiram com a viabilidade das células em relação ao controle, representado por células tratadas somente com veículo (Figuras 5.3 e 5.4). Realmente, a literatura tem mostrado que são condições de doses mais altas e tempos de tratamento mais longos que os utilizados neste estudo que afetam a viabilidade celular. Yang et al. (2003) (126) mostraram que o AAS não foi capaz de inibir o crescimento de células de câncer de boca, no entanto, a concentração máxima utilizada foi de $30 \mu \mathrm{M}$. Resultados opostos foram encontrados para o CLX, porém em concentrações bastante altas de 10 a $40 \mu \mathrm{M} \mathrm{e}$ tempos de tratamento de 4 a 6 dias. No trabalho de Rao et al. (2010) (6), o AAS foi capaz de diminuir consideravelmente a viabilidade celular nas linhagens SCC9 e SCC25 na concentração de $5 \mathrm{mM}$, no entanto no tempo de 72 horas.

Até o momento, o que se tem na literatura sobre os efeitos do AAS e CLX no CEO são estudos sobre os efeitos desses AINEs em características de comportamento celular como proliferação, apoptose, migração, invasão e metástase (6, 126, 127, 142, 143). Também foram realizados importantes estudos clínicos de fase I e II, onde o CLX mostrou-se promissor como terapia adjuvante no tratamento de CEO quando administrados $400 \mathrm{mg} /$ dia durante 6 e 12 meses, respectivamente $(8,136)$. No entanto, apenas o trabalho de Meyer et al. (128), procurou estudar os efeitos desses AINEs na modulação de citocinas inflamatórias. O estudo aqui apresentado realizou um screening, através da técnica de PCR array, da expressão de citocinas inflamatórias e seus receptores, após tratamento com AAS e CLX. Os resultados deste screening revelaram que cada linhagem respondeu de maneira diferente a cada um dos tratamentos, e mesmo dentro do mesmo tratamento, as respostas na expressão de citocinas e receptores foi diferente para cada linhagem celular (Figuras 5.5 e 5.6). De uma maneira geral, a linhagem SCC9 foi a mais responsiva à modulação de citocinas por ambos os AINEs. E diante de ambos os tratamentos mostrou mais aumento do que diminuição de expressão de citocinas. A linhagem SCC4 só mostrou diminuição e a SCC25 somente aumento de expressão, diante de ambos os tratamentos. É interessante que, em resposta ao tratamento com AAS, a linhagem SCC4 mostrou diminuição de expressão da família CXCL e a SCC9 aumento de expressão da família CCL. Infelizmente, não foi possível fazer 
qualquer relação deste último resultado com efeitos dos fármacos. Mukaida et al. (2014) (144), em recente revisão sobre o assunto, considera que é possível observar funções diferentes para ambos os grupos de quimiocinas, e até mesmo funções antagônicas para a mesma citocina. Adicionalmente, houve aumento de expressão de citocinas pró-inflamatórias como a IL-1 $\beta$, a IL-8 e o TNF, pelas linhagens SCC9 e SCC25. A modulação dessas moléculas por esses dois AINEs é bastante interessante em função de que o aumento de sua expressão está relacionado a um comportamento mais agressivo do $\operatorname{CEO}(49,72,88,91)$.

Em comum, tanto a SCC4 quanto a SCC9 mostraram diminuição de expressão de ACKR4 e CXCL10 quando tratadas com AAS.

O ACKR4 que também pode ser denominado CCRL1, CCR11 e CCX-CKR é membro do grupo de receptores atípicos de quimiocinas, do inglês atypical chemokine receptors (ACRs). Esses receptores ligam-se com alta afinidade a seus ligantes, porém, são estruturalmente incapazes de gerar os sinais necessários para que ocorra quimiotaxia. Funcionam, dessa forma, como "sequestradores" de quimiocinas, regulando o gradiente de concentração dessas moléculas e assim, o tráfego de leucócitos e maturação de órgão linfoides. Os ligantes de ACKR4 são a CCL19, a CCL21, a CCL25 e com menor afinidade a CXCL13 (145, 146). De acordo com a literatura, pelo menos as primeiras duas quimiocinas parecem estar relacionadas com aumento do potencial metastático de algumas neoplasias, inclusive do CEO $(100,147)$. Assim, o aumento de expressão deste receptor tem sido relacionado como regulador negativo de crescimento tumoral e metástase em câncer de mama, de pulmão, gástrico e hepático (148-151), no entanto, nunca houve um estudo sobre a expressão deste receptor no CEO.

Com relação a quimiocina CXCL10, foi realizado estudo mostrando que a concentração da proteína está aumentada no fluido oral de pacientes com câncer de cabeça e pescoço (91). Outro trabalho demonstrou que o aumento de expressão gênica dessa molécula está relacionado a pior resposta ao tratamento radioterápico em pacientes com CEO (92).

Este é o primeiro trabalho a realizar um screenning, através da técnica de PCR array, de citocinas inflamatórias, em células de CEO tratadas com AAS e CLX. Como os resultados mostraram que ambos os AINEs modificam a expressão gênica dessas moléculas, acredita-se que seria pertinente a realização de estudos que pudessem validar, a nível de proteína, a modulação de expressão aqui observada. 
Após a verificação de quais citocinas ou receptores estão realmente tendo sua expressão modulada pelos fármacos, estudos de silenciamento, seguidos de ensaios funcionais seriam relevantes para verificar quais as consequências da modificação de expressão dessas moléculas para o comportamento das células de CEO. 


\section{CONCLUSÃO}

Os tratamentos com AAS e CLX foram capazes de modular a expressão de citocinas inflamatórias nas três linhagens celulares estudadas. 


\section{REFERÊNCIAS ${ }^{1}$}

1. Balkwill F, Mantovani A. Inflammation and cancer: back to Virchow? Lancet. 2001;357(9255):539-45.

2. Balkwill F. Cancer and the chemokine network. Nature reviews Cancer. 2004;4(7):540-50.

3. Hanahan D, Weinberg RA. Hallmarks of cancer: the next generation. Cell. 2011;144(5):646-

74.

4. Brasil. Ministério da Saúde. Secretaria de Atenção à Saúde. Instituto Nacional de Câncer. Coordenação de Prevenção e Vigilância de Câncer. Estimativas 2014: incidência de câncer no Brasil. Rio de Janeiro: INCA; 2013.

5. Vairaktaris E, Yapijakis C, Serefoglou Z, Avgoustidis D, Critselis E, Spyridonidou S, et al. Gene expression polymorphisms of interleukins-1 beta, $-4,-6,-8,-10$, and tumor necrosis factors-alpha, beta: regression analysis of their effect upon oral squamous cell carcinoma. J Cancer Res Clin Oncol. 2008;134(8):821-32.

6. Rao SK, Pavicevic Z, Du Z, Kim JG, Fan M, Jiao Y, et al. Pro-inflammatory genes as biomarkers and therapeutic targets in oral squamous cell carcinoma. The Journal of biological chemistry. 2010;285(42):32512-21.

7. Khurram SA, Bingle L, McCabe BM, Farthing PM, Whawell SA. The chemokine receptors CXCR1 and CXCR2 regulate oral cancer cell behaviour. J Oral Pathol Med. 2014;43(9):667-74.

8. Wirth $L$, Krane JF, Li Y, Othus M, Moran AE, Dorfman DM, et al. A pilot surrogate endpoint biomarker study of celecoxib in oral premalignant lesions. Cancer Prev Res (Phila). 2008;1(5):339-48. 9. Patil VM, Noronha V, Joshi A, Muddu VK, Dhumal S, Bhosale B, et al. A prospective randomized phase II study comparing metronomic chemotherapy with chemotherapy (single agent cisplatin), in patients with metastatic, relapsed or inoperable squamous cell carcinoma of head and neck. Oral oncology. 2015;51(3):279-86.

10. Vane JR, Botting RM. Anti-inflammatory drugs and their mechanism of action. Inflammation research : official journal of the European Histamine Research Society [et al]. 1998;47 Suppl 2:S78-

87.

11. Buttar NS, Wang KK. The "aspirin" of the new millennium: cyclooxygenase-2 inhibitors. Mayo Clinic proceedings. 2000;75(10):1027-38.

12. Powles TJ, Dowsett M, Easty GC, Easty DM, Neville AM. Breast-cancer osteolysis, bone metastases, and anti-osteolytic effect of aspirin. Lancet. 1976;1(7960):608-10.

13. Kune GA, Kune $S$, Watson LF. Colorectal cancer risk, chronic illnesses, operations, and medications: case control results from the Melbourne Colorectal Cancer Study. Cancer research. 1988;48(15):4399-404.

14. Pold M, Zhu LX, Sharma S, Burdick MD, Lin Y, Lee PP, et al. Cyclooxygenase-2-dependent expression of angiogenic CXC chemokines ENA-78/CXC Ligand (CXCL) 5 and interleukin-8/CXCL8 in human non-small cell lung cancer. Cancer research. 2004;64(5):1853-60.

15. Bronger H, Kraeft S, Schwarz-Boeger U, Cerny C, Stockel A, Avril S, et al. Modulation of CXCR3 ligand secretion by prostaglandin E2 and cyclooxygenase inhibitors in human breast cancer. Breast Cancer Res. 2012;14(1):R30.

16. Fernandes JV, Cobucci RN, Jatoba CA, de Medeiros Fernandes TA, de Azevedo JW, de Araujo JM. The Role of the Mediators of Inflammation in Cancer Development. Pathol Oncol Res. 2015.

17. Maccio A, Madeddu C. The role of interleukin- 6 in the evolution of ovarian cancer: clinical and prognostic implications--a review. J Mol Med (Berl). 2013;91(12):1355-68.

18. Hugo HJ, Saunders C, Ramsay RG, Thompson EW. New Insights on COX-2 in Chronic Inflammation Driving Breast Cancer Growth and Metastasis. J Mammary Gland Biol Neoplasia. 2015.

\footnotetext{
${ }^{1}$ De acordo com o Estilo Vancouver.
} 
19. Mantovani A, Allavena P, Sica A, Balkwill F. Cancer-related inflammation. Nature. 2008;454(7203):436-44.

20. Kim SY, Kang JW, Song X, Kim BK, Yoo YD, Kwon YT, et al. Role of the IL-6-JAK1-STAT3-Oct-4 pathway in the conversion of non-stem cancer cells into cancer stem-like cells. Cell Signal. 2013;25(4):961-9.

21. Arnold KM, Opdenaker LM, Flynn D, Sims-Mourtada J. Wound healing and cancer stem cells: inflammation as a driver of treatment resistance in breast cancer. Cancer Growth Metastasis. 2015;8:1-13.

22. Bhola NE, Balko JM, Dugger TC, Kuba MG, Sanchez V, Sanders M, et al. TGF-beta inhibition enhances chemotherapy action against triple-negative breast cancer. The Journal of clinical investigation. 2013;123(3):1348-58.

23. Kurtova AV, Xiao J, Mo Q, Pazhanisamy S, Krasnow R, Lerner SP, et al. Blocking PGE2-induced tumour repopulation abrogates bladder cancer chemoresistance. Nature. 2015;517(7533):209-13.

24. Furstenberger G, Krieg P, Muller-Decker K, Habenicht AJ. What are cyclooxygenases and lipoxygenases doing in the driver's seat of carcinogenesis? International journal of cancer Journal international du cancer. 2006;119(10):2247-54.

25. Langenbach R, Loftin CD, Lee C, Tiano H. Cyclooxygenase-deficient mice. A summary of their characteristics and susceptibilities to inflammation and carcinogenesis. Annals of the New York Academy of Sciences. 1999;889:52-61.

26. Tiano HF, Loftin CD, Akunda J, Lee CA, Spalding J, Sessoms A, et al. Deficiency of either cyclooxygenase (COX)-1 or COX-2 alters epidermal differentiation and reduces mouse skin tumorigenesis. Cancer research. 2002;62(12):3395-401.

27. Rundhaug JE, Mikulec C, Pavone A, Fischer SM. A role for cyclooxygenase-2 in ultraviolet light-induced skin carcinogenesis. Molecular carcinogenesis. 2007;46(8):692-8.

28. Sales KJ, Boddy SC, Williams AR, Anderson RA, Jabbour HN. F-prostanoid receptor regulation of fibroblast growth factor 2 signaling in endometrial adenocarcinoma cells. Endocrinology. 2007;148(8):3635-44.

29. Kim BH, Kim Cl, Chang HS, Choe MS, Jung HR, Kim DY, et al. Cyclooxygenase-2 overexpression in chronic inflammation associated with benign prostatic hyperplasia: is it related to apoptosis and angiogenesis of prostate cancer? Korean journal of urology. 2011;52(4):253-9.

30. Chu J, Lloyd FL, Trifan OC, Knapp B, Rizzo MT. Potential involvement of the cyclooxygenase-2 pathway in the regulation of tumor-associated angiogenesis and growth in pancreatic cancer. Molecular cancer therapeutics. 2003;2(1):1-7.

31. Nie D. Cyclooxygenases and lipoxygenases in prostate and breast cancers. Frontiers in bioscience : a journal and virtual library. 2007;12:1574-85.

32. Liu H, Xiao J, Yang Y, Liu Y, Ma R, Li Y, et al. COX-2 expression is correlated with VEGF-C, lymphangiogenesis and lymph node metastasis in human cervical cancer. Microvascular research. 2011;82(2):131-40.

33. Halamka M, Cvek J, Kubes J, Zavadova E, Kominek P, Horacek J, et al. Plasma levels of vascular endothelial growth factor during and after radiotherapy in combination with celecoxib in patients with advanced head and neck cancer. Oral oncology. 2011;47(8):763-7.

34. Yao M, Kargman S, Lam EC, Kelly CR, Zheng Y, Luk P, et al. Inhibition of cyclooxygenase-2 by rofecoxib attenuates the growth and metastatic potential of colorectal carcinoma in mice. Cancer research. 2003;63(3):586-92.

35. Ranger GS, Thomas V, Jewell A, Mokbel K. Elevated cyclooxygenase-2 expression correlates with distant metastases in breast cancer. Anticancer Res. 2004;24(4):2349-51.

36. Kumar V AA, Fausto N, Aster JC. Robbins \& Cotran: Patologia-Bases patológicas das doenças. 8th ed. Rio de Janeiro: Elsevier; 2013.

37. Raman D, Baugher PJ, Thu YM, Richmond A. Role of chemokines in tumor growth. Cancer Lett. 2007;256(2):137-65.

38. Viola A, Luster AD. Chemokines and their receptors: drug targets in immunity and inflammation. Annual review of pharmacology and toxicology. 2008;48:171-97. 
39. Mukaida N, Baba T. Chemokines in tumor development and progression. Exp Cell Res. 2012;318(2):95-102.

40. Vinader $\mathrm{V}$, Afarinkia K. The emerging role of $\mathrm{CXC}$ chemokines and their receptors in cancer. Future Med Chem. 2012;4(7):853-67.

41. Galizia G, Orditura M, Romano C, Lieto E, Castellano P, Pelosio L, et al. Prognostic significance of circulating IL-10 and IL-6 serum levels in colon cancer patients undergoing surgery. Clin Immunol. 2002;102(2):169-78.

42. Lu CC, Kuo HC, Wang FS, Jou MH, Lee KC, Chuang JH. Upregulation of TLRs and IL-6 as a marker in human colorectal cancer. Int J Mol Sci. 2015;16(1):159-77.

43. Bondurant KL, Lundgreen A, Herrick JS, Kadlubar S, Wolff RK, Slattery ML. Interleukin genes and associations with colon and rectal cancer risk and overall survival. International journal of cancer Journal international du cancer. 2013;132(4):905-15.

44. De Simone V, Ronchetti G, Franze E, Colantoni A, Ortenzi A, Fantini MC, et al. Interleukin-21 sustains inflammatory signals that contribute to sporadic colon tumorigenesis. Oncotarget. 2015;6(12):9908-23.

45. Vaish V, Tanwar L, Kaur J, Sanyal SN. Chemopreventive effects of non-steroidal antiinflammatory drugs in early neoplasm of experimental colorectal cancer: an apoptosome study. Journal of gastrointestinal cancer. 2011;42(4):195-203.

46. Yuan A, Yang PC, Yu CJ, Chen WJ, Lin FY, Kuo SH, et al. Interleukin-8 messenger ribonucleic acid expression correlates with tumor progression, tumor angiogenesis, patient survival, and timing of relapse in non-small-cell lung cancer. Am J Respir Crit Care Med. 2000;162(5):1957-63.

47. Cho YA, Sung MK, Yeon JY, Ro J, Kim J. Prognostic role of interleukin-6, interleukin-8, and leptin levels according to breast cancer subtype. Cancer Res Treat. 2013;45(3):210-9.

48. Dethlefsen C, Hojfeldt G, Hojman P. The role of intratumoral and systemic IL-6 in breast cancer. Breast Cancer Res Treat. 2013;138(3):657-64.

49. Kulbe $\mathrm{H}$, Levinson NR, Balkwill F, Wilson JL. The chemokine network in cancer--much more than directing cell movement. Int J Dev Biol. 2004;48(5-6):489-96.

50. Mohamed MM, Al-Raawi D, Sabet SF, El-Shinawi M. Inflammatory breast cancer: New factors contribute to disease etiology: A review. J Adv Res. 2014;5(5):525-36.

51. Bieche I, Lerebours F, Tozlu S, Espie M, Marty M, Lidereau R. Molecular profiling of inflammatory breast cancer: identification of a poor-prognosis gene expression signature. Clin Cancer Res. 2004;10(20):6789-95.

52. Mohamed MM. Monocytes conditioned media stimulate fibronectin expression and spreading of inflammatory breast cancer cells in three-dimensional culture: A mechanism mediated by IL-8 signaling pathway. Cell Commun Signal. 2012;10(1):3.

53. Luca M, Huang S, Gershenwald JE, Singh RK, Reich R, Bar-Eli M. Expression of interleukin-8 by human melanoma cells up-regulates MMP-2 activity and increases tumor growth and metastasis. Am J Pathol. 1997;151(4):1105-13.

54. Arenberg DA, Kunkel SL, Polverini PJ, Glass M, Burdick MD, Strieter RM. Inhibition of interleukin-8 reduces tumorigenesis of human non-small cell lung cancer in SCID mice. J Clin Invest. 1996;97(12):2792-802.

55. Kitadai Y, Takahashi Y, Haruma K, Naka K, Sumii K, Yokozaki H, et al. Transfection of interleukin-8 increases angiogenesis and tumorigenesis of human gastric carcinoma cells in nude mice. Br J Cancer. 1999;81(4):647-53.

56. Ferrara N, Davis-Smyth T. The biology of vascular endothelial growth factor. Endocr Rev. 1997;18(1):4-25.

57. Ravi D, Ramadas K, Mathew BS, Nalinakumari KR, Nair MK, Pillai MR. Angiogenesis during tumor progression in the oral cavity is related to reduced apoptosis and high tumor cell proliferation. Oral Oncol. 1998;34(6):543-8.

58. Shi Q, Abbruzzese JL, Huang S, Fidler IJ, Xiong Q, Xie K. Constitutive and inducible interleukin 8 expression by hypoxia and acidosis renders human pancreatic cancer cells more tumorigenic and metastatic. Clin Cancer Res. 1999;5(11):3711-21. 
59. Zhang XY, Chan WY, Whitney BM, Fan DM, Chow JH, Liu Y, et al. Changes of interleukin expression correlate with Helicobacter pylori infection and lymph node metastases in gastric carcinoma. Diagn Mol Pathol. 2002;11(3):135-9.

60. Slaton JW, Inoue K, Perrotte P, El-Naggar AK, Swanson DA, Fidler IJ, et al. Expression levels of genes that regulate metastasis and angiogenesis correlate with advanced pathological stage of renal cell carcinoma. Am J Pathol. 2001;158(2):735-43.

61. Venkatakrishnan G, Salgia R, Groopman JE. Chemokine receptors CXCR-1/2 activate mitogenactivated protein kinase via the epidermal growth factor receptor in ovarian cancer cells. J Biol Chem. 2000;275(10):6868-75.

62. Li A, Varney ML, Singh RK. Expression of interleukin 8 and its receptors in human colon carcinoma cells with different metastatic potentials. Clin Cancer Res. 2001;7(10):3298-304.

63. Xie Q, Thompson R, Hardy K, DeCamp L, Berghuis B, Sigler R, et al. A highly invasive human glioblastoma pre-clinical model for testing therapeutics. J Transl Med. 2008;6:77.

64. Efimova EV, Liang H, Pitroda SP, Labay E, Darga TE, Levina V, et al. Radioresistance of Stat1 over-expressing tumour cells is associated with suppressed apoptotic response to cytotoxic agents and increased IL6-IL8 signalling. Int J Radiat Biol. 2009;85(5):421-31.

65. Wiley HE, Gonzalez EB, Maki W, Wu MT, Hwang ST. Expression of CC chemokine receptor-7 and regional lymph node metastasis of B16 murine melanoma. J Natl Cancer Inst. 2001;93(21):163843.

66. Mashino K, Sadanaga N, Yamaguchi H, Tanaka F, Ohta M, Shibuta K, et al. Expression of chemokine receptor CCR7 is associated with lymph node metastasis of gastric carcinoma. Cancer research. 2002;62(10):2937-41.

67. Ding Y, Shimada Y, Maeda M, Kawabe A, Kaganoi J, Komoto I, et al. Association of CC chemokine receptor 7 with lymph node metastasis of esophageal squamous cell carcinoma. Clin Cancer Res. 2003;9(9):3406-12.

68. Muller A, Sonkoly E, Eulert C, Gerber PA, Kubitza R, Schirlau K, et al. Chemokine receptors in head and neck cancer: association with metastatic spread and regulation during chemotherapy. International journal of cancer Journal international du cancer. 2006;118(9):2147-57.

69. Saintigny P, Massarelli E, Lin S, Ahn YH, Chen Y, Goswami S, et al. CXCR2 expression in tumor cells is a poor prognostic factor and promotes invasion and metastasis in lung adenocarcinoma. Cancer research. 2013;73(2):571-82.

70. Varney ML, Singh S, Li A, Mayer-Ezell R, Bond R, Singh RK. Small molecule antagonists for CXCR2 and CXCR1 inhibit human colon cancer liver metastases. Cancer Lett. 2011;300(2):180-8.

71. Wente MN, Keane MP, Burdick MD, Friess H, Buchler MW, Ceyhan GO, et al. Blockade of the chemokine receptor CXCR2 inhibits pancreatic cancer cell-induced angiogenesis. Cancer Lett. 2006;241(2):221-7.

72. Rhodus NL, Cheng B, Myers S, Miller L, Ho V, Ondrey F. The feasibility of monitoring NFkappaB associated cytokines: TNF-alpha, IL-1alpha, IL-6, and IL-8 in whole saliva for the malignant transformation of oral lichen planus. Molecular carcinogenesis. 2005;44(2):77-82.

73. Katakura A, Kamiyama I, Takano N, Shibahara T, Muramatsu T, Ishihara K, et al. Comparison of salivary cytokine levels in oral cancer patients and healthy subjects. Bull Tokyo Dent Coll. 2007;48(4):199-203.

74. SahebJamee M, Eslami M, AtarbashiMoghadam F, Sarafnejad A. Salivary concentration of TNFalpha, IL1 alpha, IL6, and IL8 in oral squamous cell carcinoma. Med Oral Patol Oral Cir Bucal. 2008;13(5):E292-5.

75. St John MA, Li Y, Zhou X, Denny P, Ho CM, Montemagno C, et al. Interleukin 6 and interleukin 8 as potential biomarkers for oral cavity and oropharyngeal squamous cell carcinoma. Arch Otolaryngol Head Neck Surg. 2004;130(8):929-35.

76. Chen Z, Malhotra PS, Thomas GR, Ondrey FG, Duffey DC, Smith CW, et al. Expression of proinflammatory and proangiogenic cytokines in patients with head and neck cancer. Clin Cancer Res. 1999;5(6):1369-79. 
77. Brailo V, Vucicevic-Boras V, Lukac J, Biocina-Lukenda D, Zilic-Alajbeg I, Milenovic A, et al. Salivary and serum interleukin 1 beta, interleukin 6 and tumor necrosis factor alpha in patients with leukoplakia and oral cancer. Med Oral Patol Oral Cir Bucal.

78. Rhodus NL, Cheng B, Myers S, Bowles W, Ho V, Ondrey F. A comparison of the proinflammatory, NF-kappaB-dependent cytokines: TNF-alpha, IL-1-alpha, IL-6, and IL-8 in different oral fluids from oral lichen planus patients. Clin Immunol. 2005;114(3):278-83.

79. Vucicevic Boras V, Cikes N, Lukac J, Virag M, Cekic-Arambasin A. Salivary and serum interleukin 6 and basic fibroblast growth factor levels in patients with oral squamous cell carcinoma. Minerva Stomatol. 2005;54(10):569-73.

80. Duffy SA, Taylor JM, Terrell JE, Islam M, Li Y, Fowler KE, et al. Interleukin-6 predicts recurrence and survival among head and neck cancer patients. Cancer. 2008;113(4):750-7.

81. Nagata $M$, Fujita $H$, Ida $H$, Hoshina $H$, Inoue $T$, Seki $Y$, et al. Identification of potential biomarkers of lymph node metastasis in oral squamous cell carcinoma by cDNA microarray analysis. Int J Cancer. 2003;106(5):683-9.

82. Shinriki S, Jono $\mathrm{H}$, Ota $\mathrm{K}$, Ueda $\mathrm{M}$, Kudo $\mathrm{M}$, Ota $\mathrm{T}$, et al. Humanized anti-interleukin-6 receptor antibody suppresses tumor angiogenesis and in vivo growth of human oral squamous cell carcinoma. Clin Cancer Res. 2009;15(17):5426-34.

83. Skrinjar I, Brailo V, Vidovic-Juras D, Vucicevic-Boras V, Milenovic A. Evaluation of pretreatment serum interleukin- 6 and tumour necrosis factor alpha as a potential biomarker for recurrence in patients with oral squamous cell carcinoma. Med Oral Patol Oral Cir Bucal. 2015.

84. Subbalekha K, Pimkhaokham A, Pavasant P, Chindavijak S, Phokaew C, Shuangshoti S, et al. Detection of LINE-1s hypomethylation in oral rinses of oral squamous cell carcinoma patients. Oral Oncol. 2009;45(2):184-91.

85. Gasche JA, Hoffmann J, Boland CR, Goel A. Interleukin-6 promotes tumorigenesis by altering DNA methylation in oral cancer cells. Int J Cancer.

86. Mocellin S, Rossi CR, Pilati P, Nitti D. Tumor necrosis factor, cancer and anticancer therapy. Cytokine Growth Factor Rev. 2005;16(1):35-53.

87. Jablonska E, Piotrowski L, Grabowska Z. Serum Levels of IL-1b, IL-6, TNF-a, sTNF-RI and CRP in Patients with Oral Cavity Cancer. Pathol Oncol Res. 1997;3(2):126-9.

88. Arellano-Garcia ME, Hu S, Wang J, Henson B, Zhou H, Chia D, et al. Multiplexed immunobeadbased assay for detection of oral cancer protein biomarkers in saliva. Oral Dis. 2008;14(8):705-12. 89. Andersson BA, Lewin F, Lundgren J, Nilsson M, Rutqvist LE, Lofgren S, et al. Plasma tumor necrosis factor-alpha and C-reactive protein as biomarker for survival in head and neck squamous cell carcinoma. J Cancer Res Clin Oncol. 2014;140(3):515-9.

90. Kulbe $\mathrm{H}$, Thompson R, Wilson JL, Robinson S, Hagemann T, Fatah R, et al. The inflammatory cytokine tumor necrosis factor-alpha generates an autocrine tumor-promoting network in epithelial ovarian cancer cells. Cancer Res. 2007;67(2):585-92.

91. Michiels K, Schutyser E, Conings R, Lenaerts JP, Put W, Nuyts S, et al. Carcinoma cell-derived chemokines and their presence in oral fluid. Eur J Oral Sci. 2009;117(4):362-8.

92. Rentoft M, Coates PJ, Loljung L, Wilms T, Laurell G, Nylander K. Expression of CXCL10 is associated with response to radiotherapy and overall survival in squamous cell carcinoma of the tongue. Tumour Biol. 2014;35(5):4191-8.

93. Cohen RF, Contrino J, Spiro JD, Mann EA, Chen LL, Kreutzer DL. Interleukin-8 expression by head and neck squamous cell carcinoma. Arch Otolaryngol Head Neck Surg. 1995;121(2):202-9.

94. Christofakis EP, Miyazaki H, Rubink DS, Yeudall WA. Roles of CXCL8 in squamous cell carcinoma proliferation and migration. Oral oncology. 2008;44(10):920-6.

95. Watanabe $\mathrm{H}$, Iwase $\mathrm{M}$, Ohashi $\mathrm{M}$, Nagumo $\mathrm{M}$. Role of interleukin-8 secreted from human oral squamous cell carcinoma cell lines. Oral oncology. 2002;38(7):670-9.

96. Gyanchandani R, Sano D, Ortega Alves MV, Klein JD, Knapick BA, Oh S, et al. Interleukin-8 as a modulator of response to bevacizumab in preclinical models of head and neck squamous cell carcinoma. Oral oncology. 2013;49(8):761-70. 
97. Sano D, Myers JN. Metastasis of squamous cell carcinoma of the oral tongue. Cancer Metastasis Rev. 2007;26(3-4):645-62.

98. Kim MJ, Kim KM, Kim J, Kim KN. BMP-2 promotes oral squamous carcinoma cell invasion by inducing CCL5 release. PLoS One. 2014;9(10):e108170.

99. Tsuzuki H, Takahashi N, Kojima A, Narita N, Sunaga H, Takabayashi T, et al. Oral and oropharyngeal squamous cell carcinomas expressing CCR7 have poor prognoses. Auris Nasus Larynx. 2006;33(1):37-42.

100. Shang ZJ, Liu K, Shao Z. Expression of chemokine receptor CCR7 is associated with cervical lymph node metastasis of oral squamous cell carcinoma. Oral oncology. 2009;45(6):480-5.

101. Qian Y, Wang Y, Li DS, Zhu YX, Lu ZW, Ji QH, et al. The chemokine receptor-CXCR2 plays a critical role in the invasion and metastases of oral squamous cell carcinoma in vitro and in vivo. J Oral Pathol Med. 2014;43(9):658-66.

102. Romanini J, Mielcke TR, Leal PC, Figueiredo CP, Calixto JB, Morrone FB, et al. The role of CXCR2 chemokine receptors in the oral squamous cell carcinoma. Invest New Drugs.

2012;30(4):1371-8.

103. Allaj V, Guo C, Nie D. Non-steroid anti-inflammatory drugs, prostaglandins, and cancer. Cell \& bioscience. 2013;3(1):8.

104. Stone E. An account of the success of the bark of the willow in the cure of agues.

Philosophical Transactions of the Royal Society. 1763;53:195-200.

105. Dreser H. Pharmakologisches über Aspirin (Acetyisalicylsaüre). Pflügers Arch. 1899;76:306-

18.

106. Roth GJ, Stanford N, Majerus PW. Acetylation of prostaglandin synthase by aspirin.

Proceedings of the National Academy of Sciences of the United States of America. 1975;72(8):3073-6.

107. DeWitt DL, el-Harith EA, Kraemer SA, Andrews MJ, Yao EF, Armstrong RL, et al. The aspirin and heme-binding sites of ovine and murine prostaglandin endoperoxide synthases. The Journal of biological chemistry. 1990;265(9):5192-8.

108. Botting RM. Vane's discovery of the mechanism of action of aspirin changed our understanding of its clinical pharmacology. Pharmacol Rep. 2010;62(3):518-25.

109. Picot D, Loll PJ, Garavito RM. The X-ray crystal structure of the membrane protein prostaglandin H2 synthase-1. Nature. 1994;367(6460):243-9.

110. Wong E, Bayly C, Waterman HL, Riendeau D, Mancini JA. Conversion of prostaglandin G/H synthase-1 into an enzyme sensitive to PGHS-2-selective inhibitors by a double His513 --> Arg and lle523 --> val mutation. The Journal of biological chemistry. 1997;272(14):9280-6.

111. Zarraga IG, Schwarz ER. Coxibs and heart disease: what we have learned and what else we need to know. Journal of the American College of Cardiology. 2007;49(1):1-14.

112. Simon LS, Lanza FL, Lipsky PE, Hubbard RC, Talwalker S, Schwartz BD, et al. Preliminary study of the safety and efficacy of SC-58635, a novel cyclooxygenase 2 inhibitor: efficacy and safety in two placebo-controlled trials in osteoarthritis and rheumatoid arthritis, and studies of gastrointestinal and platelet effects. Arthritis and rheumatism. 1998;41(9):1591-602.

113. Thun MJ, Namboodiri MM, Heath CW, Jr. Aspirin use and reduced risk of fatal colon cancer. The New England journal of medicine. 1991;325(23):1593-6.

114. Luk GD. Prevention of gastrointestinal cancer--the potential role of NSAIDs in colorectal cancer. Schweizerische medizinische Wochenschrift. 1996;126(19):801-12.

115. Kutchera W, Jones DA, Matsunami N, Groden J, McIntyre TM, Zimmerman GA, et al. Prostaglandin $\mathrm{H}$ synthase 2 is expressed abnormally in human colon cancer: evidence for a transcriptional effect. Proceedings of the National Academy of Sciences of the United States of America. 1996;93(10):4816-20.

116. Gustafson-Svard C, Lilja I, Hallbook O, Sjodahl R. Cyclooxygenase-1 and cyclooxygenase-2 gene expression in human colorectal adenocarcinomas and in azoxymethane induced colonic tumours in rats. Gut. 1996;38(1):79-84.

117. Tsujii M, DuBois RN. Alterations in cellular adhesion and apoptosis in epithelial cells overexpressing prostaglandin endoperoxide synthase 2. Cell. 1995;83(3):493-501. 
118. Sheng H, Shao J, Kirkland SC, Isakson P, Coffey RJ, Morrow J, et al. Inhibition of human colon cancer cell growth by selective inhibition of cyclooxygenase-2. The Journal of clinical investigation. 1997;99(9):2254-9.

119. Oshima M, Dinchuk JE, Kargman SL, Oshima H, Hancock B, Kwong E, et al. Suppression of intestinal polyposis in Apc delta716 knockout mice by inhibition of cyclooxygenase 2 (COX-2). Cell. 1996;87(5):803-9.

120. Steinbach G, Lynch PM, Phillips RKS, Wallace MH, Hawk E, Gordon GB, et al. The effect of celecoxib, a cyclooxygenase-2 inhibitor, in familial adenomatous polyposis. New Engl J Med. 2000;342(26):1946-52.

121. Phillips RK, Wallace MH, Lynch PM, Hawk E, Gordon GB, Saunders BP, et al. A randomised, double blind, placebo controlled study of celecoxib, a selective cyclooxygenase 2 inhibitor, on duodenal polyposis in familial adenomatous polyposis. Gut. 2002;50(6):857-60.

122. Lynch PM, Ayers GD, Hawk E, Richmond E, Eagle C, Woloj M, et al. The safety and efficacy of celecoxib in children with familial adenomatous polyposis. Am J Gastroenterol. 2010;105(6):1437-43.

123. Lang M, Gasche C. Chemoprevention of colorectal cancer. Dig Dis. 2015;33(1):58-67.

124. Sareddy GR, Geeviman K, Ramulu C, Babu PP. The nonsteroidal anti-inflammatory drug celecoxib suppresses the growth and induces apoptosis of human glioblastoma cells via the NFkappaB pathway. J Neurooncol. 2012;106(1):99-109.

125. Kwak YE, Jeon NK, Kim J, Lee EJ. The cyclooxygenase-2 selective inhibitor celecoxib suppresses proliferation and invasiveness in the human oral squamous carcinoma. Annals of the New York Academy of Sciences. 2007;1095:99-112.

126. Yang $\mathrm{CY}$, Meng CL, Liao CL, Wong PY. Regulation of cell growth by selective COX-2 inhibitors in oral carcinoma cell lines. Prostaglandins Other Lipid Mediat. 2003;72(3-4):115-30.

127. Li WZ, Huo QJ, Wang XY, Xu F. Inhibitive effect of celecoxib on the adhesion and invasion of human tongue squamous carcinoma cells to extracellular matrix via down regulation of MMP-2 expression. Prostaglandins Other Lipid Mediat. 2010;93(3-4):113-9.

128. Meyer C, Pries R, Wollenberg B. Established and novel NF-kappaB inhibitors lead to downregulation of TLR3 and the proliferation and cytokine secretion in HNSCC. Oral oncology. 2011;47(9):818-26.

129. Sagiv E, Sheffer M, Kazanov D, Shapira S, Naumov I, Kraus S, et al. Gene expression following exposure to celecoxib in humans: pathways of inflammation and carcinogenesis are activated in tumors but not normal tissues. Digestion. 2011;84(3):169-84.

130. Chen JJ, Yao PL, Yuan A, Hong TM, Shun CT, Kuo ML, et al. Up-regulation of tumor interleukin8 expression by infiltrating macrophages: its correlation with tumor angiogenesis and patient survival in non-small cell lung cancer. Clin Cancer Res. 2003;9(2):729-37.

131. Liu Y, Liu A, Li H, Li C, Lin J. Celecoxib inhibits interleukin-6/interleukin-6 receptor-induced JAK2/STAT3 phosphorylation in human hepatocellular carcinoma cells. Cancer Prev Res (Phila). 2011;4(8):1296-305.

132. Bergman $M$, Djaldetti $M$, Salman $H$, Bessler H. Inflammation and colorectal cancer: does aspirin affect the interaction between cancer and immune cells? Inflammation. 2011;34(1):22-8.

133. Juarez Olguin H, Flores Perez J, Lares Asseff I, Loredo Abdala A, Carbajal Rodriguez L. Comparative pharmacokinetics of acetyl salicylic acid and its metabolites in children suffering from autoimmune diseases. Biopharm Drug Dispos. 2004;25(1):1-7.

134. Krishnaswami S, Hutmacher MM, Robbins JL, Bello A, West C, Bloom BJ. Dosing celecoxib in pediatric patients with juvenile rheumatoid arthritis. J Clin Pharmacol. 2012;52(8):1134-49.

135. Wirth LJ, Haddad RI, Lindeman NI, Zhao X, Lee JC, Joshi VA, et al. Phase I study of gefitinib plus celecoxib in recurrent or metastatic squamous cell carcinoma of the head and neck. J Clin Oncol. 2005;23(28):6976-81.

136. Saba NF, Hurwitz SJ, Kono SA, Yang CS, Zhao Y, Chen Z, et al. Chemoprevention of head and neck cancer with celecoxib and erlotinib: results of a phase ib and pharmacokinetic study. Cancer Prev Res (Phila). 2014;7(3):283-91. 
137. Stark LA, Din FV, Zwacka RM, Dunlop MG. Aspirin-induced activation of the NF-kappaB signaling pathway: a novel mechanism for aspirin-mediated apoptosis in colon cancer cells. FASEB J. 2001;15(7):1273-5.

138. Yin MJ, Yamamoto Y, Gaynor RB. The anti-inflammatory agents aspirin and salicylate inhibit the activity of I(kappa)B kinase-beta. Nature. 1998;396(6706):77-80.

139. Nagelschmitz J, Blunck M, Kraetzschmar J, Ludwig M, Wensing G, Hohlfeld T.

Pharmacokinetics and pharmacodynamics of acetylsalicylic acid after intravenous and oral administration to healthy volunteers. Clin Pharmacol. 2014;6:51-9.

140. Niederberger E, Tegeder I, Vetter G, Schmidtko A, Schmidt H, Euchenhofer C, et al. Celecoxib loses its anti-inflammatory efficacy at high doses through activation of NF-kappaB. FASEB J. 2001;15(9):1622-4.

141. Paulson SK, Hribar JD, Liu NW, Hajdu E, Bible RH, Jr., Piergies A, et al. Metabolism and excretion of [(14)C]celecoxib in healthy male volunteers. Drug Metab Dispos. 2000;28(3):308-14.

142. Park IS, Jo JR, Hong H, Nam KY, Kim JB, Hwang SH, et al. Aspirin induces apoptosis in YD-8 human oral squamous carcinoma cells through activation of caspases, down-regulation of $\mathrm{Mcl}-1$, and inactivation of ERK-1/2 and AKT. Toxicol In Vitro. 2010;24(3):713-20.

143. Fujii R, Imanishi Y, Shibata K, Sakai N, Sakamoto K, Shigetomi S, et al. Restoration of Ecadherin expression by selective Cox- 2 inhibition and the clinical relevance of the epithelial-tomesenchymal transition in head and neck squamous cell carcinoma. J Exp Clin Cancer Res. 2014;33:40.

144. Mukaida N, Sasaki S, Baba T. Chemokines in cancer development and progression and their potential as targeting molecules for cancer treatment. Mediators Inflamm. 2014;2014:170381.

145. Graham GJ. D6 and the atypical chemokine receptor family: novel regulators of immune and inflammatory processes. Eur J Immunol. 2009;39(2):342-51.

146. Nibbs RJ, Graham GJ. Immune regulation by atypical chemokine receptors. Nat Rev Immunol. 2013;13(11):815-29.

147. Schimanski CC, Bahre R, Gockel I, Junginger T, Simiantonaki N, Biesterfeld S, et al. Chemokine receptor CCR7 enhances intrahepatic and lymphatic dissemination of human hepatocellular cancer. Oncol Rep. 2006;16(1):109-13.

148. Zeng $X H$, Ou ZL, Yu KD, Feng LY, Yin WJ, Li J, et al. Coexpression of atypical chemokine binders (ACBs) in breast cancer predicts better outcomes. Breast Cancer Res Treat. 2011;125(3):715-27.

149. Wu FY, Fan J, Tang L, Zhao YM, Zhou CC. Atypical chemokine receptor D6 inhibits human nonsmall cell lung cancer growth by sequestration of chemokines. Oncol Lett. 2013;6(1):91-5.

150. Zhu Z, Sun Z, Wang Z, Guo P, Zheng X, Xu H. Prognostic impact of atypical chemokine receptor expression in patients with gastric cancer. J Surg Res. 2013;183(1):177-83.

151. Shi JY, Yang LX, Wang ZC, Wang LY, Zhou J, Wang XY, et al. CC chemokine receptor-like 1 functions as a tumour suppressor by impairing CCR7-related chemotaxis in hepatocellular carcinoma. J Pathol. 2015;235(4):546-58. 
ANEXO A - Parecer do Comitê de Ética em Pesquisa da Faculdade de Odontologia da Universidade de São Paulo

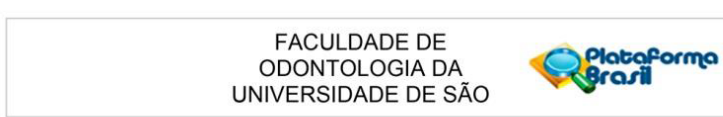

PARECER CONSUBSTANCIADO DO CEP

DADOS DO PROJETO DE PESQUISA

Titulo da Pesquisa: Efeito das citocinas no comportamento de linhagens celulares de carcinoma Pesquisador: Fabio Daumas Nunes

Área Temática:

Versão: 1

CAAE: 06999713.7 .0000 .0075

Instituicăo Proponente: Universidade de Sao Paulo

Instituiçāo Proponente: Universidade de Sao Patro

DADOS DO PARECER

Número do Parecer: 224.084

Data da Relatoria: 20/03/2013

Apresentação do Projeto:

Nas últimas duas décadas vários estudos têm mostrado evidèncias sobre a participação da inflamação no desenvolvimento de muitos tipos de câncer. As citocinas e quimiocinas inflamatórias são componentes importantes dessa relação sendo produzidas por vários tipos celulares, inclusive pelas próprias células neoplásicas. Apesar de não se conhecer em profundidade o efeito desse processo no câncer de cavidade oral, mais especificamente no carcinoma epidermoide (CEO), algumas citocinas como a IL-6 e IL-8 já foram identificadas nesta neoplasia, porém pouco se conhece sobre a eficácia da terapia com anti-inflamatórios na atividade destas citocinas.

Objetivo da Pesquisa:

Avaliar a expressão de citocinas e quimiocinas em linhagens celulares de carcinoma epidermoide de boca após tratamento com anti-inflamatórios, $\mathrm{e}$

efeito da expressão diferencial no comportamento dessas células.

Avaliaçăo dos Riscos e Beneficios:

Os benefícios estão relacionados com o melhor entendimento da relação câncer/inflamação no carcinom epidermoide oral. Não há riscos, uma vez que o estudo será feito em linhagens celulares comerciais.

\section{Endereco: Av Prof Lineu Prestes $2227 \quad$ CEP: $05.508-900$
Bairro: Cidade Universitaraia}

UF: SP
Telefone:

E-mail: cept@@usp.br
FACULDADE DE ODONTOLOGIA DA UNIVERSIDADE DE SÃO

Comentários e Consideraçöes sobre a Pesquisa:

A pesquisa é importante, relevante e atende as normas éticas.

Consideraçōes sobre os Termos de apresentaçăo obrigatória:

Por ser realizada com células comerciais, dispensa o uso do TCLE.

Recomendações:

Não há recomendações.

Conclusōes ou Pendências e Lista de Inadequaçōes:

Aprovada.

Tendo em vista a legislação vigente, devem ser encaminhados ao CEP-FOUSP relatórios parciais anuais referentes ao andamento da pesquisa e relatório final ao término do trabalho. Qualquer modificaçăo do projeto original deve ser apresentada a este CEP, de forma objetiva e com justificativas, para nova apreciação.

Situação do Parecer:

Aprovado

Necessita Apreciação da CONEP:

Não

Consideraçōes Finais a critério do CEP:

SAO PAULO, 20 de Março de 2013

Assinador por:
Maria Gabriela Haye Biazevic
(Coordenador)

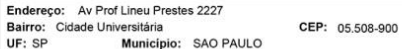

UF: SP
Telefone: (11)3091-7960
Fax: (11)3091-7814 
ANEXO B - Desenho da placa utilizada nos experimentos de PCR array (RT ${ }^{2}$ Profiler PCR Array PAHS-022ZA (QIAGEN)

\begin{tabular}{|l|l|l|l|l|l|l|l|l|l|l|l|l|}
\hline & $\mathbf{1}$ & $\mathbf{2}$ & $\mathbf{3}$ & $\mathbf{4}$ & $\mathbf{5}$ & $\mathbf{6}$ & $\mathbf{7}$ & $\mathbf{8}$ & $\mathbf{9}$ & $\mathbf{1 0}$ & $\mathbf{1 1}$ & $\mathbf{1 2}$ \\
\hline A & C5 & C5AR1 & ACKR2 & CCL1 & CCL11 & CCL13 & CCL14 & CCL15 & CCL16 & CCL17 & CCL18 & CCL19 \\
\hline B & CCL2 & CCL20 & CCL21 & CCL22 & CCL23 & CCL24 & CCL25 & CCL26 & CCL27 & CCL28 & CCL3 & CCL4 \\
\hline C & CCL5 & CCL7 & CCL8 & CCR1 & CCR10 & CCR2 & CCR3 & CCR4 & CCR5 & CCR6 & CCR7 & CCR8 \\
\hline D & CCR9 & ACKR4 & CCRL2 & CKLF & CMKLR1 & CMTM1 & CMTM2 & CMTM3 & CMTM4 & CX3CL1 & CX3CR1 & CXCL1 \\
\hline E & CXCL10 & CXCL11 & CXCL12 & CXCL13 & CXCL14 & CXCL16 & CXCL2 & CXCL3 & CXCL5 & CXCL6 & CXCL9 & CXCR1 \\
\hline F & CXCR2 & CXCR3 & CXCR4 & CXCR5 & CXCR6 & ACKR3 & DARC & FPR1 & GPR17 & HIF1A & IL16 & IL1B \\
\hline $\mathbf{G ~}$ & IL4 & IL8 & PF4V1 & PPBP & SLIT2 & TLR2 & TLR4 & TNF & TYMP & XCL1 & XCL2 & XCR1 \\
\hline H & ACTB & B2M & GAPDH & HPRT1 & RPLPO & HGDC & RTC & RTC & RTC & PPC & PPC & PPC \\
\hline
\end{tabular}


ANEXO C - Tabelas com os genes diferencialmente expressos pelas células da linhagem SCC4, SCC9 e SCC25 tratadas com AAS ou CLX em relação ao respectivo controle.

Tabela 1 - Genes diferencialmente expressos pelas células da linhagem SCC4 tratadas com AAS em relação ao controle.

\begin{tabular}{cccc}
\hline Gene & Fold regulation & Categoria & Função \\
\hline C5AR1 & 6.92 & B & outro \\
CCL15 & 2.01 & B & quimiocina \\
CCL22 & 2.48 & B & quimiocina \\
CCL3 & 3.48 & B & quimiocina \\
CCL4 & 2.97 & B & quimiocina \\
CXCR5 & 2.17 & B & receptor de quimiocina \\
GPR17 & 8.16 & A & outro \\
IL16 & 2.91 & B & quimiocina \\
& & & \\
CCL17 & -3.79 & B & quimiocina \\
CCL25 & -2.61 & B & quimiocina \\
CCR8 & -2.28 & B & receptor de quimiocina \\
CCR9 & -3.11 & B & receptor de quimiocina \\
ACKR4 & -2.41 & OK & receptor de quimiocina \\
CCRL2 & -2.84 & B & receptor de quimiocina \\
CXCL10 & -2.46 & OK & quimiocina \\
CXCL11 & -2.13 & OK & quimiocina \\
CXCL14 & -2.65 & B & quimiocina \\
CXCL3 & 2.22 & OK & quimiocina \\
CXCL6 & -2.08 & OK & quimiocina \\
IL4 & -2.28 & B & interleucina \\
IL8 & -2.41 & OK & quimiocina \\
PF4V1 & -3.53 & OK & quimiocina \\
PPBP & -3.37 & B & quimiocina \\
XCL2 & -2.06 & & quimiocina \\
\hline & & &
\end{tabular}


Tabela 2 - Genes diferencialmente expressos pelas células da linhagem SCC9 tratadas com AAS em relação ao controle.

\begin{tabular}{|c|c|c|c|}
\hline Gene & Fold regulation & Categoria & Função \\
\hline CCL17 & 3.82 & $\bar{B}$ & quimiocina \\
\hline CCL19 & 2.16 & B & quimiocina \\
\hline CCL20 & 5.01 & OK & quimiocina \\
\hline CCL26 & 2.80 & $\mathrm{~B}$ & quimiocina \\
\hline CCL27 & 2.09 & OK & quimiocina \\
\hline CCL28 & 4.13 & OK & quimiocina \\
\hline CCL3 & 4.61 & $A$ & quimiocina \\
\hline CCL4 & 5.93 & $A$ & quimiocina \\
\hline CCR10 & 3.75 & $\mathrm{~B}$ & receptor de quimiocina \\
\hline CCR3 & 2.52 & $B$ & receptor de quimiocina \\
\hline CCR7 & 2.27 & $\mathrm{~B}$ & receptor de quimiocina \\
\hline CKLF & 3.01 & OK & outro \\
\hline CMTM3 & 2.03 & OK & outro \\
\hline CMTM4 & 3.23 & OK & outro \\
\hline CXCR2 & 7.07 & B & receptor de quimiocina \\
\hline CXCR5 & 2.35 & $\mathrm{~B}$ & receptor de quimiocina \\
\hline FPR1 & 2.23 & B & outro \\
\hline IL16 & 3.06 & $B$ & quimiocina \\
\hline IL1 $\beta$ & 13.30 & OK & interleucina \\
\hline $1 \mathrm{~L} 8$ & 2.05 & OK & quimiocina \\
\hline C5 & -3.35 & $\mathrm{~B}$ & outro \\
\hline CCR4 & -2.35 & $\mathrm{~B}$ & receptor de quimiocina \\
\hline CCR9 & -2.12 & B & receptor de quimiocina \\
\hline ACKR4 & -2.31 & $A$ & receptor de quimiocina \\
\hline CX3CL1 & -2.36 & B & quimiocina \\
\hline CXCL10 & -2.04 & OK & quimiocina \\
\hline CXCL9 & -5.52 & B & quimiocina \\
\hline CXCR4 & -3.24 & B & receptor de quimiocina \\
\hline
\end{tabular}


Tabela 3 - Genes diferencialmente expressos pelas células da linhagem SCC25 tratadas com AAS em relação ao controle.

\begin{tabular}{cccc}
\hline Gene & Fold regulation & Categoria & Função \\
\hline CCL13 & 8.26 & $\mathrm{~B}$ & quimiocina \\
CCL17 & 3.03 & B & quimiocina \\
CCL4 & 3.23 & B & quimiocina \\
CCR4 & 2.05 & B & receptor de quimiocina \\
CCR6 & 2.08 & B & receptor de quimiocina \\
CCR7 & 6.67 & B & receptor de quimiocina \\
CMTM3 & 2.54 & OK & outro \\
CMTM4 & 2.51 & OK & outro \\
CXCL3 & 3.27 & OK & quimiocina \\
CXCR5 & 10.86 & B & receptor de quimiocina \\
IL16 & 2.50 & B & quimiocina \\
IL1 & 2.72 & OK & interleucina \\
IL4 & 3.80 & OK & interleucina \\
TLR4 & 2.46 & OK & outro \\
& & & \\
ACKR2 & -2.71 & B & receptor de quimiocina \\
CCL11 & -2.48 & B & quimiocina \\
CCL25 & -2.40 & B & quimiocina \\
CCR1 & -2.41 & B & receptor de quimiocina \\
CCR3 & -2.22 & B & receptor de quimiocina \\
CKLF & -2.25 & OK & outro \\
CXCL13 & -4.59 & B & quimiocina \\
FPR1 & -2.07 & OK & outro \\
TLR2 & -2.26 & OK & outro \\
\hline
\end{tabular}


Tabela 4 - Genes diferencialmente expressos pelas células da linhagem SCC4 tratadas com CLX em relação ao controle.

\begin{tabular}{cccc}
\hline Gene & Fold regulation & Categoria & Função \\
\hline ACKR2 & 2.2081 & $\mathrm{~B}$ & receptor de quimiocina \\
CCL3 & 2.6993 & $\mathrm{~B}$ & quimiocina \\
CCR10 & 6.009 & $\mathrm{~B}$ & receptor de quimiocina \\
CCR2 & 3.7823 & $\mathrm{~B}$ & receptor de quimiocina \\
CCR9 & 3.1551 & $\mathrm{~B}$ & receptor de quimiocina \\
CCRL2 & 3.6582 & $\mathrm{~B}$ & receptor de quimiocina \\
CMKLR1 & 2.2766 & $\mathrm{~B}$ & outro \\
CMTM1 & 2.5351 & OK & outro \\
CMTM2 & 2.9405 & $\mathrm{~B}$ & outro \\
CXCL14 & 4.5883 & $\mathrm{~B}$ & quimiocina \\
CXCR3 & 8.7942 & $\mathrm{~B}$ & quimiocina \\
FPR1 & 2.6728 & $\mathrm{~B}$ & outro \\
GPR17 & 2.1587 & $\mathrm{~B}$ & outro \\
& & & \\
CCL18 & -2.6234 & $\mathrm{~B}$ & quimiocina \\
CCL27 & -7.8979 & $\mathrm{~B}$ & quimiocina \\
CCR4 & -2.8614 & $\mathrm{~B}$ & receptor de quimiocina \\
CCR6 & -2.7447 & $\mathrm{~B}$ & receptor de quimiocina \\
PF4V1 & -2.4801 & OK & quimiocina \\
\hline
\end{tabular}


Tabela 5 - Genes diferencialmente expressos pelas células da linhagem SCC9 tratadas com CLX em relação ao controle.

\begin{tabular}{cccc}
\hline Gene & Fold regulation & Categoria & Função \\
\hline CCL28 & 3.3116 & OK & quimiocina \\
CCR1 & 3.3391 & B & receptor de quimiocina \\
CCR6 & 2.2502 & B & receptor de quimiocina \\
CMTM1 & 4.8777 & OK & outro \\
CMTM3 & 32.1133 & A & outro \\
CMTM4 & 3.5264 & OK & outro \\
CXCL16 & 2.2470 & OK & quimiocina \\
CXCL3 & 2.2427 & A & quimiocina \\
CXCL5 & 4.7060 & B & quimiocina \\
CXCR6 & 7.4021 & A & quimiocina \\
ACKR3 & 2.2336 & A & receptor de quimiocina \\
IL13 & 2.4705 & OK & interleucina \\
SLIT2 & 3.2246 & OK & outro \\
TLR2 & 2.8493 & OK & outro \\
TLR4 & 5.3284 & A & outro \\
TNF & 6.7651 & A & citocina \\
TYMP & 21.321 & A & outro \\
& & & outro \\
HIF1A & $-2,0371$ & OK & quimiocina \\
XCL2 & -2.1784 & OK & \\
\hline
\end{tabular}

Tabela 6 - Genes diferencialmente expressos pelas células da linhagem SCC25 tratadas com CLX em relação ao controle

\begin{tabular}{cccc}
\hline Gene & Fold regulation & Categoria & Função \\
\hline CCL20 & 2.4794 & $\mathrm{~A}$ & quimiocina \\
CCL22 & 2.1002 & $\mathrm{~B}$ & quimiocina \\
CCL25 & 4.7699 & $\mathrm{~B}$ & quimiocina \\
CCL3 & 2.1542 & $\mathrm{~B}$ & quimiocina \\
& & & \\
CCR1 & 4.1161 & $\mathrm{~B}$ & receptor de quimiocina \\
CCR4 & 2.5335 & $\mathrm{~B}$ & receptor de quimiocina \\
CXCL16 & 2.3239 & OK & quimiocina \\
CXCL9 & 2.0068 & $\mathrm{~A}$ & quimiocina \\
IL16 & 4.0865 & $\mathrm{~B}$ & quimiocina \\
SLIT2 & 2.6069 & $\mathrm{~B}$ & outro \\
XCL1 & 8.9935 & $\mathrm{~B}$ & quimiocina \\
XCL2 & 2.1727 & OK & quimiocina \\
CXCR5 & -3.5256 & & B \\
\hline
\end{tabular}

